University of Rhode Island

DigitalCommons@URI

Open Access Dissertations

1993

\title{
A Structural Equation Model of a Set of Operationalized Cognitive Social Learning Variables and Citizen Participation in Neighborhood Organizations
}

Donald R. Whitworth

University of Rhode Island

Follow this and additional works at: https://digitalcommons.uri.edu/oa_diss

\section{Recommended Citation}

Whitworth, Donald R., "A Structural Equation Model of a Set of Operationalized Cognitive Social Learning Variables and Citizen Participation in Neighborhood Organizations" (1993). Open Access Dissertations. Paper 919.

https://digitalcommons.uri.edu/oa_diss/919

This Dissertation is brought to you for free and open access by DigitalCommons@URI. It has been accepted for inclusion in Open Access Dissertations by an authorized administrator of DigitalCommons@URI. For more information, please contact digitalcommons-group@uri.edu. 


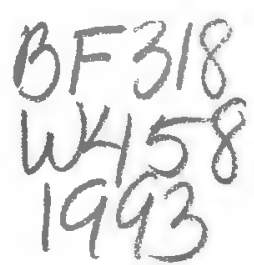

A STRUCTURAL EQUATION MODEL OF A SET OF OPERATIONALIZED COGNITIVE SOCIAL LEARNING VARIABLES AND CITIZEN PARTICIPATION IN NEIGHBORHOOD ORGANIZATIONS BY DONALD R. WHITWORTH

A DISSERTATION SUBMITTED IN PARTIAL FULFILLMENT OF THE REQUIREMENTS FOR THE DEGREE OF DOCTOR OF PHILOSOPHY IN PSYCHOLOGY

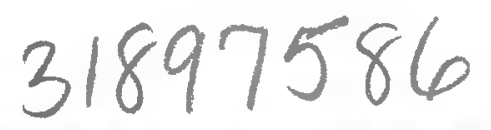

UNIVERSITY OF RHODE ISLAND 


\section{ABSTRACT}

This study investigated the salience of a cognitive social learning model for understanding the process by which an individual decides to participate in a neighborhood association. An operationalized set of cognitive social learning variables served as the dimensions of the hypothesized model to explain citizen participation. The subjects included 229 adult (18 years and older) Jewish Israelis. Of the total pool of subjects, 112 were graduates of Project Renewal neighborhood activist training programs who were interview in their homes. The remaining 117 subjects were nonactivists randomly selected from the same neighborhoods as the activists. Forty nine percent of the subjects were men; $86 \%$ were married. Questions asked by trained interviewers included a set of operationalized cognitive social learning variables and self reported indices of participation. The data were analyzed using a structural equation modeling statistical method which allowed one to simultaneously examine hypothesized relationships among several constructs in an integrated statistical model. Two different models of participation were tested then compared using three indices of model to data fit; the Comparative Fit Index, ML ChiSquare Statistic, and The RMSR. A Chi- Square Difference test was then conducted to determine the best model to data fit between the two models. For Model 1, the indicators of goodness of fit supported a reasonable fit between the model and data. However, for Model 2, indicators of goodness of fit supported an excellent model to data fit. The majority of the predictions were found to be significant. 
Importance of Neighborhood, Perceived Skills and Past Experience Relevant to Participation, and Political Cynicism were found to be directly related to an individual's decision to participate in a neighborhood association. In addition, Perceived Skills and Past Experience Relevant to Participation and Political Cynicism were found to be significant mediating variables in the process of deciding to participate. Given these results the cognitive social learning approach is proposed as an acceptable framework by which the process by which an individual decides to participate might be understood. 


\section{ACKNOWLEDGEMENT}

I wish to express my deepest appreciation to Paul Florin, Ph.d. whose support, mentoring and guidance have helped shape my professional identity and has made possible this dissertation. He has also been a true friend throughout my tenure at the University of Rhode Island, offering whatever necessary to ensure the successful completion of my education. Appreciation is also extended to Lisa Harlow, Ph.d. who trained me in the use of the statistical analysis used and who helped and encouraged me in the most troubling stages of data analysis. The contributions of John Stevenson are difficult to number. He also has provided a strong since of guidance and direction as well as valuable expertise in the area of theoretical conceptualization. Many thanks to Dick Purnell, ED.d. who took the time to provide an alternative view and a much needed alternative perspective throughout this project. Finally, and most importantly, I wish to send heart felt thanks to my wife, Joyce and children, Zach and Dakota, who gave up much family time in order to make this project possible. I owe them many missed hours and hope to be able to repay them in triplicate throughout our future together. 


\section{TABLE OF CONTENTS}

List of Tables. ........................ . . .

List of Figures. . . . . . . . . . . . . . . . . viii

Introduction. . . . . . . . . . . . . . . . . 1

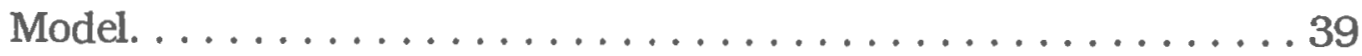

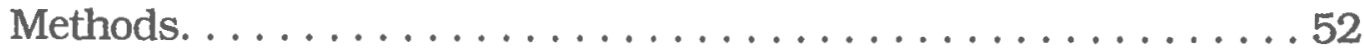

Procedure. ........................ 52

Subjects. . . . . . . . . . . . . . . . . .

Variables. ......................... 54

Analysis. . . . . . . . . . . . . . . . . . 69

Results. ...........................70

Model 1. . . . . . . . . . . . . . . . . . . 74

Model $2 \ldots \ldots \ldots \ldots \ldots \ldots \ldots \ldots \ldots$

Discussion. ........................... 103

Bibliography. .............................119 


\section{LIST OF TABLES}

Table 1 Factor Analysis of CSLV Items. . . . . . . . 59

Table 2 Items Predicting Latent Variable Construction Competencies. . . . . . . . . . . . . . . 60

Table 3 Items Predicting the Latent Variable Encoding. .61

Table 4 Items Predicting the Latent Variable

Expectancies. . . . . . . . . . . . . . 62

Table 5 Items Predicting the Latent Variable Subjective Stimulus Values. . . . . . . . . . . . . . .63

Table 6 Items Predicting the Latent Variable Self

Regulation. ................... 64

Table 7 Items Comprising the Latent Dependent Variable

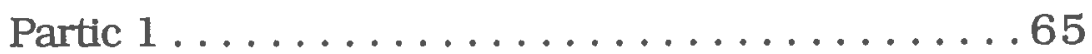

Table 8 Items Comprising the Latent Dependent Variable:

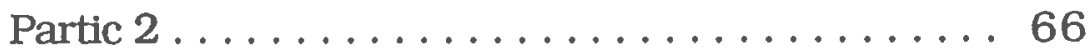

Table 9 Items Comprising the Latent Dependent Variable: Partic 3. . . . . . . . . . . . . . . . . . 69

Table 10 Means, Ranges, and Standard Deviations Measured Variables. . . . . . . . . . . . . . . . . . . . .72

Table 11 Factor Loadings for Full Model 25 Variables. . . . 73

Table 12 Model 1 Factor Loadings - Reduced Model . . . . 76

Table 13 Measurement Equations, Standard Errors, Z scores, and Significance Levels Model 1. . . . 77-78 


\section{LIST OF TABLES}

Table 14 Model 2 Factor Loadings for Full Model 25 Variables. . . . . . . . . . . . . . . . . 88

Table 15 Model 2 Factor Loadings Reduced Model. . . . . . 89

Table 16 Measurement Equations, Standard Errors, Z scores, and Significance Levels. . . . . . . . . . . 90-91

Table 17 Model Comparisons. .............. 101 


\section{LIST OF FIGURES}

Figure 1 Model 1 Latent Structural Model. . . . . . . . . . . . . 50

Figure 2 Model 2 Latent Structural Model. . . . . . . . . . . . . 51

Figure 3 Model 1 Standardized Solution With Coefficients. . . .86

Figure 4 Model 2 Standardized Solution With Coefficients. . . .102 


\section{Introduction}

Citizen participation in voluntary community organizations provides inherent advantages and benefits for both the individual and the community (Florin \& Wandersman, in press 1992). However, despite positive impacts, community organizations generally suffer recruitment difficulties (Prestby, Wandersman, Florin, Rich, \& Chavis, 1990). Thus knowing who is likely to participate and why they participate can provide valuable information to these organizations. There is a large body of research on specific demographic variables associated with participation. This literature is, however, limited in explanatory power (Parkum \& Parkum 1980; Smith 1975;. 1974). Edwards \& White (1980) for example, found that only $8 \%$ of the variance in participation in community associations could be accounted for by 11 different demographic variables (Edwards \& White, 1980). This avenue of inquiry also does little to advance the understanding of the process of citizen participation. (Edwards \& White, 1980; Florin \& Wandersman, 1984; Wandersman, Florin Freidman, \& Meir, 1987; Florin, Wandersman, Freidman \& Meir, 1989). Information and research pertaining to the personality, psychosocial, and attitudinal variables associated with participation is scarce (Parkum \& Parkum 1980; Smith 1975; Tomeh, 1974). More recent research (Florin \& Wandersman, 1984; Wandersman, Florin, Freidman, \& Meir, 1987; Florin, Jones, \& Wandersman, 1988) has 
provided an additional $14 \%$ of unique variance to the prediction of citizen participation uttlizing Cognitive Social Learning Variables proposed by Mischel (1973) and operationalized specifically for participation. Based upon this work, Florin and Wandersman (1984) have suggested further investigation of the CSLVs because they provide a framework which examines the process used by an individual when deciding to participate.

It is the purpose of this investigation to further examine the process by which individuals decide to participate in voluntary community organizations through examining the causal relationships between and among the Cognitive Social Learning Variables and citizen participation in a neighborhood association using a structural equation modeling procedure.

\section{Citizen Participation: A Definition}

There is a large body of research related to participation in a variety of activities throughout society. More specifically, citizen participation has been conceptualized in a variety of ways for a variety of purposes. This is so much the case that Langton, (1978) proposed that "the definition and analysis of citizen participation is a formidable task." (Langton, 1978, pg. 13).

A considerable body of research on the subject of citizen participation exists in many different fields including, planning. political science, public administration, architecture, environment- 
behavioral studies, community organizations and industrial organization. Concurrently, participation is dealt with in many different environmental contexts and levels such as the neighborhood, the work environment, and in cities to name a few (Churchman, 1987). As a result, there are many different definitions of citizen participation. A representative sample of these definitions follows.

In the area of political science, Verba \& Nie (1980) define citizen participation by private citizens as those activities that are directly aimed at influencing the selection of government personnel and or the selection of actions they take.

From the area of community organizations Brager \& Specht, (1973) define citizen participation as the ways and means by which people who are not elected or appointed officials of agencies and government influence decisions about programs and policies which affect their lives.

According to Mulvihill, (1980), in the area of planning, participation is defined in situations where an individual has an option to be a party to an agreement which must be sought within reasonable limits, before a decision affecting him or her can be effected.

In the area of Education, Nettles (1991) suggests that particpation can be defined as Community Involvement. Community Involvement consists of the actions organizations and individuals take 
to promote student development. Such community involvement is typically defined by the types of roles that community participants play in supporting students.

In the area of community psychology, Heller, Price, Reinhartz, Riger \& Wandersman (1984) have defined citizen participation as individuals taking part in decision making in the institutions, programs, and environments that affect them. Participation is commonly used in a way to suggest taking part in an activity, usually in association with other people and implies that power and influence are important elements in the use of the term participation. Important to this definition is the focus on the individual and the broad range of situations in which citizen participation may take place. Accordingly, participation occurs in many settings and contexts both in relation to government and in other nongovernmental institutions within the community.

Langton (1978) has provided a definition of citizen participation based upon the formal derivatives of the words "citizen" and "participation" in the English language. By combining the etymological roots of the two words, Langton defines citizen participation as "the purposeful activities in which citizens take part in relation to government." (Langton, 1978, pg. 17). This definition excludes activities which people participate in relation to other social institutions. Langton thus distinguishes between citizen participation 
in which people relate to the state and participation in which people relate to social institutions.

Langton (1978) distinguishes among four types or categories of citizen participation which are natural outgrowths of his definition. Accordingly, Electoral participation is initiated and controlled by government in order to elect representatives and vote on pertinent political candidate or in support or opposition to an issue. Obligatory participation refers to the mandatory responsibilities that are the legal obligations of the citizenship. This category includes such activities such as paying ones taxes, jury duty, and military service. Citizen Involvement refers to activities which are initiated and controlled by government to improve and/or to gain support for decisions, programs, or services. This category involves such activities as public hearings, consultations with advisory committees, and attitudinal surveys. Citizen Action refers to citizen initiated and controlled participation for the purposes which they (the citizens) determine. This type of citizen participation would be seen in associations involved in lobbying, public advocacy, and protest (Langton, 1978).

For the purposes of this research, citizen participation will most closely reflect the definitions offered by Heller, et. al. (1984) in the area of community psychology and "Citizen Action" as defined by Langton (1978). Citizen participation will reflect citizen initiated and controlled activities in which individuals take part in the decision 
making process in the institutions, programs, and environments that affect them. This definition has been selected due to the attention payed to the impact of the individual in citizen participation and the broad range of situations and contexts in which participation may take place.

\section{Voluntary Associations: A Typology}

The diversity of groups which have been categorized as voluntary organizations is enormous and the various conceptualizations of this term in the organizational literature are inconsistent (Prestby, 1984, Perrow, 1979, Smith \& Freeman, 1978). A number of classifying schemes or typologies have been developed by scholars in order to better understand voluntary organizations. Such typologies classify organizations by size, internal structure, independence/dependence on external control, sources of support, location, members characteristics, and member relations (Smith and Freeman, 1978, Prestby, 1884).

Babchuk and Gordon (1962), differentiate organizations by their expressive and instrumental orientations. In this scheme expressive organizations perform functions which are immediately gratifying and are focused on the individual members. These are rather restrictive organizations and have little accessibility. Instrumental organizations are more focused on task-related activities which extend outside the organization, such as providing a service or producing a product. 
According to Gordon and Babchuk (1962), an association can be instrumental/expressive only when it provides appropriate structure or opportunity for both forms of activity to occur.

Clark and Wilson (1961) classified organizations on the basis of incentives which are described as material, solidary, or purposive and which are available to individuals as an inducement to contribute to their activity or group. Even though voluntary associations may offer all three kinds of incentives for participation, these authors believe the distinguishing feature of the voluntary association is its reliance on solidary incentives such as sociabllity, fun, and prestige.

Blau and Scott (1962) divide voluntary organizations into types according to who is the beneficiary of the associations activities. For example, they suggest that "Mutual benefit associations benefit their memberships, service organizations benefit clients, common wealth organizations benefit the public-at-large, and in business organizations, owners reap the primary benefits (Blau and Scott, 1962).

Polister and Pattison (1979) proposed a taxonomy of community organizations based upon an empirically created community group scale designed to determine various types of voluntary community organizations. Based upon cluster analysis, Polister and Pattison (1979) provide four group types. Self-interest groups advocate a cause or promote the interest of a defined population. Examples of this group type include, labor unions, professional groups, political 
organizations, and neighborhood development groups. Social

Communion groups may have some organized activittes but primarily provide a setting for people to congregate and interact in a supportive fashion. Examples of this type of group would be a church, synagogue group, community centers, youth groups, and fraternal lodges or veterans organizations. Civic development groups are primarily aimed at developing the social skills of members through community service or other organized activities. This would include such groups as charity or welfare organizations, business and civic groups. Recreational groups are action oriented and provide a casual, unregulated atmosphere for brief involvement. Such groups would include sports teams, social or card playing groups, and a country club. Smith and Freeman (1978), have proposed that voluntary associations can be defined as a nonprofit, private group, unattached to government control, which an individual joins by choice. Members are not born into such associations as they are into the family or the church, nor drafted into them as in the case with the military, nor are they require to join in order to make living as is frequently the case with professional groups." (Smith and Freeman, 1978, pg. viii).

Finally, participation by individuals in neighborhood associations should be differentiated from participation in other types of voluntary associations. According to Florin and Wandersman (1981), a useful distinction is the notion of organizations within communities as 
opposed to community organizations. The former comprise those fraternal social and voluntary organizations which include such organizations as the Lions Club, churches, and the Red Cross, to name but a few, and which may involve many residents from a particular neighborhood. These organizations are embedded within the community's institutional structure. Participation in such organizations has been called "social participation" (Langton, 1978) and is the type of participation usually measured in the studies of volunteerism. Participation in community organizations, on the other hand, involves membership in a group that purposefully seeks to represent the interests of a given locale and aims to take action to help maintain or improve the locale. This type of participation, in which citizens initiate and control activity for purposes they themselves have determined has been called "citizen action" (Langton, 1978).

For the purposes of this research, voluntary association will be defined here along the lines proposed by Smith \& Freeman, (1978), Florin and Wandersman (1981) and Polister and Pattison (1979) referring to organizations/associations (used interchangeably throughout this research) which are comprised of individuals who enter by choice, who are not born into such organizations, nor are they required to join. These groups/associations are defined by their advocacy of a cause or promotion of the interests of a defined 
population. Thus by definition, voluntary organizations/associations will exclude any business or trade association, and adjuncts to profit making institutions which differ in function and legal status from voluntary associations as defined in this research.

Benefits of Participation:

Participation in voluntary community organizations provides advantages and benefits for both the individual and community (Wandersman \& Florin, in press). However, despite these positive impacts, community organizations generally suffer recruitment difficulties and are vulnerable to rapid decline into inactlvity (Florin, Chavis, Wandersman, \& Rich, 1992) . It is thus important to understand the important benefits citizen participation promotes. A review of the literature pertaining to the benefits of citizen participation follows.

In their examination of the literature pertaining to the potential benefits of citizen participation in small scale voluntary community associations, such as neighborhood and neighborhood associations, Wandersman and Florin, (in press) identify three domains of possible benefit. These domains include: 1) benefits in terms of the physical and social conditions; 2) benefits in terms of interpersonal relations; 3). and benefits to the individual citizen participators. The three domains can be translated into the Community, the organization, and the individual. 
There are many case examples in the literature of how neighborhood organization have successfully changed local physical conditions (Alterman \& Frenkel, 1985; Cassidy, 1980; Draisen, 1983; Godschalk \& Zersel, 1983; Harris, 1984; National Commission on Neighborhood, 1979: Rohe \& Gotes; 1981, 1982; Schoenenberg \& Rosenbaum, 1980; Wooley 1985). These impacts range from relatively simple clean up and beautification programs, to home repair, maintenance and improvement programs to more ambitious building projects.

Considerable research pertaining to the physical condition of the neighborhood indicates that the condition of the neighborhood is related to one's desire to move, one's confidence in one's neighborhood, and the degree of satisfaction one feels with their neighborhood (Ahlbrandt \& Cunningham 1979; Zehner 1972; Miller, et. al. 1979).

Wandersman, Unger, Florin, \& Chavis (1992) found that over time perceptions of neighborhood problems of residents living in neighborhoods with neighborhood associations went down while their overall satisfaction with the neighborhood increased. The results of their research indicated that neighborhood associations can be associated with positive effects on the physical environment and that changes in physical conditions are reflected in the perceptions of residents. 
Deterioration in the physical conditions of one's environment has also been shown to effect one's willingness to invest finanically and to the fear of loss of previous such investments. This can degenerate into a lessening of investments and a downward spiral (Geotze, 1979). It can be said that investments in the physical environment (eg. home, business, etc.) can have a stabilizing effect through increasing owner confidence and satisfaction. Wandersman, et al. (1992) found that residents who had functioning neighborhood associations were more likely to invest in home improvements, demonstrating a confidence in financial investments in their home which as found less frequently among those residents residing on neighborhoods without neighborhood associations (Wandersman, Unger, Florin, \& Chavis, 1992).

Communities may also benefit from citizen participation in community organizations through a specific association's involvement in the delivery of social services provided to community residents. According to Wandersman and Florin (in press) the actual vehicle used for service delivery varies greatly across associations, yet studies indicate that service delivery increases in a majority of cases where associations become involved in such delivery. For example, Yin and Yates (1974) reviewed 2125 case studies of decentralization and concluded that service delivery improved in $72 \%$ of the cases, with the most improvement occurring where residents had the most 
control over the services provided.

In terms of interpersonal relationships and improvements in neighboring behaviors, Unger and Wandersman (1983) demonstrated that participation in a neighborhood associations significantly increased the degree of neighboring. In a longitudinal design, neighboring was assessed prior to and after neighborhood associations were formed. Results indicated that residents who became members of a neighborhood association showed a significant increase in neighboring. In comparison, the neighboring behaviors of those individual who did not participate in neighborhood associations stayed the same.

Further support for the contention that neighboring is increased by participation in a neighborhood association is provided by the Block Booster Project. Data pertaining to neighboring behavior indicate that neighboring of participants in block associations was significantly higher than for non participants. Wandersman and Florin (in press 1992) suggest that this would indicate that a benefit for those members who participate in neighborhood associations is increased neighboring. However, this would not be the case for those individuals who chose not to participate.

Although benefits to the individual are seldom stated objectives or goals of voluntary community associations, none the less, there is a growing body of evidence that such is the case. For example, 
participation can result in changes in the participants' attitudes and beliefs about aspects of the environment, including towards ones' neighbors, municipal services or the government in general (Wandersman \& Florin 1990). Ahlbrandt (1984) found statistically significant correlations between participation in a neighborhood organizations and the belief that neighbors are interested in neighborhood problems. Furthermore, Cole (1974) reported that participation in various neighborhood programs increased trust and confidence in the government in general.

Further support for the benefit of citizen participation in voluntary community association, specifically neighborhood association, is provide by Chavis, Florin, Rich \& Wandersman (1987). Utilizing data collected in the conduct of the Block Booster Project, these authors found that members of block associations had significantly more positive attitudes toward their block than did those individuals who selected not to participate in a block association. As well, Chavis, et al (1987) found that members were more likely to think their block compared favorably with other blocks, to feel that conditions had improved and would continue to improve on their block, to express a higher sense of community with others on the block and to plan on staying on the block longer. (Chavis, Florin, Rich, \& Wandersman, 1987).

Wandersman, Unger, Florin, \& Chavis (1992), utilizing 
longitudinal data for a one year period, compared neighborhoods with neighborhood associations to neighborhood those without neighborhood associations in the Neighborhood Participation Project. They found that the positive ratings of the neighborhood for those neighborhoods with association went up, while ratings went down for neighborhoods without associations. Further evidence of the benefit of participation was indicated by the evidence of increased perceptions of severity of neighborhood problems for those neighborhoods without neighborhood associations and decreased perceptions of severity of neighborhood problems in neighborhoods with associations (Wandersman, Unger, Florin \& Chavis, 1992).

Finally, research in the area of change in the participants' view of self (e.g. self efficacy, Bandura 1986) indicate that participation in a community association can and does increase the participants' perceptions of self efficacy in such domains as personal and political self efficacy (Cole 1974; 1981; Levens 1968; Verba \& Nie, 1972; Zurcher, 1970). Wandersman and Florin (in press) citing results of the Block Booster Project, found that members of block associations were significantly more likely than nonmembers to demonstrate expectations of collective efficacy such as thinking that residents can solve neighborhood problem by working together and expecting that residents would intervene in the neighborhood to maintain social control. 


\section{Demographic Variables as Predictors of Participation}

Given the benefits of citizen participation, it seems both relevant and important to understand who participates in such organizations as well as why they participate (Florin \& Wandersman 1984;

Wandersman, Florin, Meir \& Freidman, 1986; Florin \& Wandersman 1990).

The question of who participates in community associations has been addressed historically through the systematic study of the demographic characteristics of those individuals who select to participate in a variety of community associations. At its earliest stage of development, prediction of citizen participation focused on specific demographic characteristics of participants. According to Edwards \& White (1980) these variables proved to be less predictive than one would hope. However, even though demographic variables have accounted for little of the overall variance in these investigations, it is noteworthy to document the contributions this research has made to the initial understanding of participation in voluntary community associations.

The specific demographic variables/characteristics which have been the focus of previous research include gender, age, marital status, education and occupation (Smith, 1975). Florin and Wandersman (1984) in their study of the predictive power of a set of traditional demographic variables found that individuals were more 
likely to participate in a neighborhood association if they were older, married, a home owner, female and from a smaller household. Florin, Freidman, Wandersman \& Meir (1986) utilizing a set of demographic variables traditionally studied in the prediction of participation established that variables such as age, education, and marital status were able to minimally discriminate leaders of neighborhood association from nonmembers and members from nonmembers of neighborhood associations.

In their study of the predictive power of a set of traditional demographic and personality variables vs the power of variables operationalized from Mischel (1973), Florin, Jones, \& Wandersman (1988) found that both sets of variables were comparable in the ability to predict participation in a neighborhood association. However it was also found that the demographic variables important in the prediction of participation were home ownership, marriage, age, and length of residence. As well, those of the highest participation levels were also higher on social status as indicated by occupation and education.

More recent research focusing on demographic characteristics of students who participate in community service volunteering by Fitch (1987) indicates that those students most likely to be participants in community services associations are involved in community service prior to entering college and have parents who were role models for volunteering. 
The work of Fitch (1991) is an effort to understand the differences between volunteers and nonvolunteering students utilizing both demographic and motivational variables. He found that students who were most likely to volunteer were social majors and women. Interestingly, Fitch found that those students who had yet to declare a major were least likely to be volunteers in off campus as well as campus wide volunteer associations.

In a national study of citizen participation in mutual aide associations in Canada, Gottleib (1991) found that $58 \%$ of mutual aide volunteers were women between the ages of 25-44 years. As well, those most likely to be volunteers in mutual aid associations were college educated, from middle-class homes, married or living with a romantic partner, employed and found to be participating in more than one service association.

In addition to the variables previously cited, race and socioeconomic status have been investigated in an effort to better understand their relationship to participation as it exists in the urban residential environment (Wandersman, Florin, Freidman, \& Meir 1986). Research by Alfred Scoble (1968); Hyman \& Wright, 1971; \& Milbrath, 1965, has been suggestive of the fact that middle class people are more likely to participate in community associations than the lower classes. Piven (1968) suggests a possible explanation of this phenomenon can be proposed by the isolation of at lease three factors 
which have affected urban lower class participation. These factors include: the overwhelming nature of concrete needs, low self efficacy or little belief in their (the lower classes) ability to impact their environment, and having little experience and commensurate skills in leadership roles. As regards race, Orum (1966), and Williams, Babchuk \& Johnson (1967) found that when socioeconomic status is statistically controlled, the effects of race are such that Blacks are more likely to participate in voluntary associations than their White counterparts (Orum 1966; Williams, Babchuk \& Johnson, 1973). This notion is further supported by the work of Olsen (1970) who also controlled for socioeconomic status and found blacks' participatory behavior across a variety of social and political settings to be higher than whites.

Some investigators have attempted to combine various demographic variables in an effort to strengthen their ability to predict participation. The findings of these investigation have been disappointing even though they have demonstrated modest but significant correlations with various types of participation (Vassar, 1978; Edwards \& White, 1980; Florin \& Wandersman 1984; Wandersman Florin, Meir, \& Freidman, 1986). For example, Williams \& Ortega (1986) investigated the relationship of nine demographic variables with membership in five different types of voluntary associations and found that only two variables, race and education were 
positively related to all types of participation. Furthermore, Edwards $\&$ White (1980) found that only $8 \%$ of the variance in participation in community associations could be accounted for by eleven different demographic variables.

\section{Personality \& Attitudinal Variables As Correlates of Participation}

Although there is a rather large body of research on the specific demographic variables associated with participation, research regarding the personality and attitudinal variables associated with participation is scarce and limited (Parkum \& Parkum, 1980; Smith 1975; Tomeh, 1974). Early in the study of this phenomenon, looking at personality variables, Bronnfenbrenner (1960) and Gough (1952), noted an individuals' verbal and relational capabilities were associated with participation in community activities. Gurin, et.al. ( 1969) found a persons' Locus of Control to be related to political activity and Sanger \& Alker, (1972) found the same personality variable, Locus of Control to be related to activity in the women's movement. In a separate attitudinal study, Carr, Dixon, and Ogles (1976) have shown that membership in a neighborhood organization is positively correlated with favorable attitudes toward the neighborhood.

Research in the area of altruism has also provided some insight into the phenomenon of citizen participation. For example, Unger (1991) in an effort to investigate the relationships of altruism to 
volunteerism found support for the proposition that altruism, defined as self sacrifice with no apparent reward, is an important motive in volunteering behavior. This altruistic motive is based not on self rewards, but rather on providing benefits for others. According to Unger (1991), rather than responding to potential personal benefits, the volunteer, in general, appears to be motivated by his or her perception of the needs of the community.

Fitch (1987) in his investigation of the characteristics and motivations of college students who volunteer for community service associations, found that students were significantly more likely to volunteer for altruistic reasons than for egotistic reasons. Furthermore, those subjects who scored high on a religiosity scale rated altruistic reasons for volunteering for community service more often than any other group.

Latting, (1990), in a study of the motivational differences between black and white volunteers found that black volunteers were significantly more likely to volunteer for altruistic purposes than white volunteers, while white volunteers were significantly more likely to volunteer to learn something new.

A cross cultural study conducted by Wandersman, Florin, Freidman \& Meir, (1987) designed to investigate who participates in a neighborhood association and why such people participate, found that 14 of 16 social psychological variables were parallel across two 
cultures, the United States and Israel. Their research indicates that the perceptions, attitudes, and beliefs associated with participation in a neighborhood association are the same across the two cultures. Wandersman et.al (1987) found that for both cultures, individuals were more likely to participate in a neighborhood association when they reported higher levels of: involvement in community activities, political self efficacy, citizen duty, perceived problems in the neighborhood, sense of community in the neighborhood, importance of sense of community, personal influence in the neighborhood, self esteem, and importance of the neighborhood.

In their comparisons of members and nonmembers of neighborhood/neighborhood associations, Wandersman, et.al. (1987) suggest that their findings indicate that members did not differ from nonmembers in terms of their overall ratings of satisfaction with their residential environment than nonmembers. However, members did see more specific problems in their residential environment than nonmembers. This would indicated that members perceived a greater need for change than nonmembers. Members also differed significantly from nonmembers in terms of the perceived importance of the residential environment. Members, due to a more significant perception of importance, would thereby be motivated to participate. Finally Wandersman, et.al. (1987) found that there were significant differences in the perceptions in personal influence and general belief 
in political efficacy. Members perceptions of their own ability to act successfully were greater than nonmembers.

Cost-Benefit approaches based upon political economy theory (Moe, 1980; Olson, 1965; Rich 1980) have also been proposed as a means of understanding why people participate. This theory suggests that a social exchange takes place in organizations in such a way that participants will invest their energy in the organizations only if they expect to receive some benefits. Accordingly, Widmer (1984) has proposed an incentive barrier model of cittzen participation which proposes incentives for participation. Material incentives are tangible rewards that are expected to result from participation. Social incentives are tanglble rewards which are expected to be the consequence of associating with others in the participatory process. Developmental incentives are intangible personal rewards which are expected to accompany participation. Ideological incentives are intangible rewards which are expected to accompany efforts to achieve goals which do not directly benefit the participant but which rather result from working toward something.

Wandersman, Florin, Freidman, \& Meir (1987) found two benefits (helping others and personal gains) and two costs (opportunity costs and organizational frustration) in their cross cultural study of cittizen participation. According to Wandersman, et.al. (1987) the absolute ratings of the members and nonmembers agreed 
in terms of the greatest benefits of participation. Both groups rated making a contribution and helping others as the greatest benefits of participation. However, nonmembers reported somewhat more personal gain for members than members reported receiving. Wandersman et.al., suggest their findings point to the hypothesis that nonmembers may not participate because they think costs are higher than members actually report.

Prestby, Wandersman, Florin, Rich, \& Chavis (1990) in their work with the Block Booster Project, developed individual level benefits and cost items as well as organizational level measures of incentive and cost management strategies based upon social exchange and political economy theory and voluntary organization research. In their study these variables were examined in 29 block associations. Prestby et.al. found results consistent with the findings of Wandersman, et.al. (1987). For example, two benefit factors consisting of personal and social/communal benefits and two cost factors comprised of personal and social/organizational costs were found. In terms of benefits, Prestby et.al. found that the most active participants reported receiving significantly more social/communal benefits and personal benefits than less active participants, with personal benefits best distinguishing the most active participants. Their research suggests that personal benefits, such as learning new skills, may be likely to be exclusive to the participants who are active 
at the highest levels due to the fact that these benefits are only available to those who participate. In terms of costs, Prestby et.al. report that the least active participants reported experiencing significantly more of all costs and significantly more of the social/organizational type costs than more active participants.

\section{Cognitive Social Learning Variables and Participation}

According to Florin and Wandersman (in press) when taken as a whole, the social psychological and cost/benefit results lend empirical support to Henig's (1982) three step-stage model of mobilization. Henig proposes that the individual perceives a condition, evaluates it as important to his or her well-being and calculates that something can be done about it. Florin \& Wandersman (1984) postulate that a framework is needed which examines the process of participation. Unlike utilizing empirically based variables which have no theoretical underpinnings, they suggest a theory is needed which examines the internal processes by which an individual decides whether or not to participate (Florin \& Wandersman, 1984). Florin \& Wandersman (1984) suggest operationalization of Mischel's cognitive social learning variables as an alternative approach to predicting and understanding participation.

The cognitive social learning variables (CSLVs) postulated by Mischel $(1973,1977)$ serve as a heuristic underpinning of an alternative approach to understanding and predicting participation 
proposed by Florin and Wandersman (1984). Mischel (1973) synthesized the cognitive learning variables from constructs about persons which were developed in the areas of cognitive psychology and social learning theory. He suggests that these cognitive social learning variables should not be conceptualized as traits and that they are not capable of predicting broad cross situational behavioral differences between persons. However, "these variables provide useful ways of conceptualizing and studying how the person constructs his or her complex behavior patterns in interaction with the conditions of his or her life." (p. 341). Mischel's variables can be described as follows:

1. Construction competencies. This variable refers to the person's cognitive and behavioral capabilities. More generally, these would form a person's skills which allow for the successful completion of specific behaviors or tasks. This is also recognized as the individual's perceived self-efficacy. In this study Construction Competencies is represented by the individuals perceived Skills for successful participation and Past participation experiencies. (See Table 2, pg 61) 2. Encoding strategies. This person variable suggests that an individual must first perceive, code, and then categorize each environment or situation he/she enters prior to acting. Thus, the processes of selective attention, interpretation, and categorization allow and influence the person to control the impact that stimuli have 
on his or her behavior. In this study, Encoding is represented by the individual's Perception of Neighborhood Problems. See Table 3, pg. 62)

3. Expectancies. In each situation/environment individuals may project the outcome of any given behavior. This is an outcome variable and refers to the individual's subjective evaluation of outcome possibilities and guides the selection of a given response which is expected to be most likely to lead to a subjectively valued outcome. In this study Expectancies is represented by the individual's Political Cynicism. (See Table 4, pg. 63)

4. Subjective stimulus values. This variable refers to the value placed upon an expected outcome. Thus, even though two individuals may have identical expectancies in a given situation, they may value the outcome much differently. This would account for different behaviors in the same situation. In this study Subjective Stimulus is represented by the individual's belief in the importance of the nieghborhood and sense of community. (See Table 5, pg. 64)

5. Self-regulatory systems and plans. This variable suggests that an individual will regulate his or her behavior by self-imposed guidelines. While there will be external consequences for any given behavior in a particular situation, the individual also sets his/her personal goals and reacts with self evaluation, criticism/satisfaction, given how well his/her behavior corresponds to the given criteria. In this study Self- 
regulatory Systems and Plans is represented by the individual's level of Citizens' Duty.

Mischel's approach to understanding an individual's behavior is at the center of the longstanding debate in psychology pertaining to the prediction of human behavior across situations. This debate has many proponents, and focuses on the influences on behavior and its prediction; predicting behavior has long been considered important. The traditional approach to this problem has focused on the contributions of internal factors such as traits or external factors such as the situation on behavior.

According to Endler \& Magnusson (1976) the study of traits has dominated personality research and theory for a number of years. Proponents of the traditional trait model propose that traits are the prime determinants of behavior and serve as a predispositional basis for apparent response-response consistencies of behavior in different situations. Thus, Allport (1937) conceived of traits as tendencies or predispositions to respond that were not linked to specific stimuli or responses, but were general and enduring. Cattell (1965), a more recent trait theorist, proposed a differentiation of traits. He believed that traits could be divided into two primary categories, surface and source traits. Surface traits were proposed as clusters of overt trait responses that overlap, while source traits were defined as the underlying causal entities that determine the surface responses which 
may be general or specific in nature.

The position of the psychodynamic theories have also focused upon person factors as important determinants of behavior in various situations. This position is very similar to that proposed by trait theorists. However, the psychodynamic theorist is concerned primarily with personality structure, dynamics and development. They propose that interpsychic conflicts among the id, ego, and superego create anxiety which then causes the individual to develop mechanisms of defense which help to ward off or defend against this anxiety. Again, it is important to note that behavior is determined by internal forces which both create and motivate behavior.

The situationalists believe that the stimuli in the situation, or the situation factors, are the determinants of human behavior. According to Endler and Magnusson (1976) this is basically a stimulus-response approach. For example, Skinner $(1953,1960)$ refuses to infer internal motives, drives, or traits and focuses on empirical analysis of the stimulus (reinforcements) conditions and the reinforcement contingencies that shape human behavior. The more contemporary social learning theorists such as Bandura (1977), Rotter (1950), and Mischel (1973) focus on what the individual does rather than on underlying traits, motives or dispositions.

The modern interactionists model (Bowers 1973; Endler 1973, 1975, 1976; Endler \& Magnusson 1976; Magnusson \& Endler 1976; 
Mischel 1973, 1977), emphasizes the importance of person - situation interactions in personality. According to Endler \& Magnusson (1976) "Behavior involves an indispensable, continuous interaction between individuals and the situations they encounter." (Endler \& Magnusson, 1976, p. 958). Accordingly, the individual is both influenced by the situation which s/he encounters, but also acts to influence the situation by selecting which situation $\mathrm{s} / \mathrm{he}$ will perform, thereby influencing the character of that situation. The basic elements of this interactionists model can be summarized as follows:

1. Actual behavior is a function of a continuous process of multidirectional interaction or (feedback) between the individual and the situations he or she encounters.

2. The individual is an intentional, active agent in this interactive process.

3. On the person side of the interaction, cognitive factors are the essential determinants of behavior although emotional factors do play a role.

4. On the situation side, the psychological meanings of the situations for the individual is the important determining factor. (Endler \& Magnusson, 1976, p. 4.)

As a major force within the modern interactionist model in psychology, Mischel's (1973) conceptualization of the mechanism of interaction begins with the recognition that the environment contains 
a potential flood of stimuli with which the individual must deal. In order to operate efficiently and effectively in the environment, the individual must avoid an overwhelming overload and must perceive, process select and interpret certain stimuli. For Mischel (1973), these filtering mechanism are best thought of as cognitive processes which are "psychological products within the individual of cognitive development and social learning experiences." (p. 265). According to Mischel's position, the attributes of the individual could be linked to the basic psychological processes rather than traits. "Person variables are linked to the basic psychological processes that regulate or guide how a person will behave in particular contexts." (Mischel, 1984, p. 295)

The number of variables proposed by Mischel emphasizes the importance of multiple causation in that behavior is the result of many variables. This also implies that differences between individuals in any given situation can be the result of differences on any one variable or combination of variables within the person. Thus, to focus research on a specific variable in the study of human behavior can lead to distortions of understanding and prediction.

The power of situations is also recognized by Mischel as is the active role of the individual in selecting situations in which to perform. He suggests that situations can be conceived of as strong or weak to the extent that they permit the idiosyncratic pattern of the 
individual's psychological mechanisms to emerge. The individual not only reacts to the environmental stimuli, but often actively selects certain situation and modifies conditions through choices, cognitions and actions.

According to Florin, Wandersman, Freidman, \& Meir (1992), in an interactionist psychology that stresses the inseparability of person and situation in determining behavior, research approaches that measure each aspect separately can be less than satisfying. They propose that cognitive social learning variables may provide the potential to move us beyond the difficulty associated with the research focused on separate parts of the behavioral equation. They suggest "that when the cognitive social learning variables are operationalized in terms of a particular situation or type of situation, they enable us to see the individual's perception, construction, and organization of the situation that is simultaneously influenced by both idiosyncratic factors and the situation." (Florin, Wandersman, Freidman, \& Meir, 1992, p. 9). In this approach, the psychologically significant situation for an individual is assessed rather than attempting to identify objective situational factors. From an interactionist frame of reference and as proposed by Florin, Wandersman, Freidman, \& Meir (1992) this approach identifies the individual's meaning ascribed to a situation as the most influential situational factor affecting the person's behavior. This then is an attempt to utilize a person - by- situation unit as the 
unit of analysis. According to the cognitive social learning perspective "This implies the inseparability of person and situation and shifts the unit of study away from global traits inferred from behavioral signs to the individual's cognitive activities and behavioral patterns studied in relation to the specific conditions that evoke, maintain, and modify them and which they, in turn, change." (Mischel, 1984, p. 294)

This Cognitive Social Learning approach has formed the basis for the investigation of citizen participation in voluntary associations in several research projects (Florin, \& Wandersman 1984; Florin, Mednick, \& Wandersman 1986; Florin, Jones, \& Wandersman, 1988; and Florin, Freidman, Wandersman, \& Meir, 1992) which have demonstrated the utility of the approach. An examination of the specific studies will shed light on the important contribution an operationalized set of cognitive social learning variables make to the understanding of the process by which an individual decides to participate in a voluntary association, or a specific situation.

Florin and Wandersman (1984) were the first to operationalize all five of Mischel's person variables in one study. In this study, two sets of independent variables were compared for their ability to predict participation. The first set, Set A, consisted of traditional individual difference demographic variables often used in participation studies (e.g. race, sex, age, \& SES), other demographic variables relevant to participation in this context, (e.g. home ownership, length 
of residence,) and traditional personality variables (e.g. locus of control and self esteem). The personality variables were selected based upon the hypothesis individuals who felt better about and themselves and felt more able to influence their environment might be more likely to participate. Florin and Wandersman (1984) indicate that there is a problem with this approach due to its lack of a theoretically grounded explanation using quantitative data. The approach depends upon simple empirical predictability.

The second set of variables, Set B, were designed to operationalize Mischel's cognitive social learning variables, construction competencies, encoding strategies, expectancies, subjective stimulus values, and self-regulatory systems and plans.

Florin \& Wandersman (1984) found that the traditional demographic and personality variables accounted for approximately $14 \%$ of the variance in participation. On the other hand, Set B, the operationalized cognitive social learning variables accounted for $19 \%$ of the variance. The combined sets, $A+B$ accounted for a total of $28 \%$ of the variance associated with participation. As well, Set B accounted for more of the unique variance than Set A (14\% versus $9 \%$ respectively).

This initial exploration of operationalized CSLVs demonstrated a statistically significant and important contribution to the understanding of why people choose to participate in community 
associations.

In a similar design, Florin, Mednick, \& Wandersman (1986) investigated the characteristics of leaders by examining variables which distinguish leaders, members and nonmembers in neighborhood organizations. Utilizing a set of demographic and personality variables and a set of operationalized (Florin \& Wandersman 1884) cognitive social learning variables these researchers were able to demonstrate that the operationalized cognitive social learning variables accounted for $21 \%$ of the variance in the criterion variable while the traditional demographic and personality variables accounted for $19 \%$ of the variance in participation. When the two sets were combined into a single set, they successfully accounted for $29 \%$ of the variance in the criterion variable. Testing for the unique variance associated with each set indicated that $10 \%$ of the unique variance in participation associated with the cognitive social learning variables would be lost should the traditional set of demographic and personality variables be used as the sole predictors of participation. Similarly, $8 \%$ of the unique variance associated with the traditional variables would be lost should the cognitive social learning variables be used alone. While the sets were similar in contribution to the prediction equation, Florin, Mednick, \& Wandersman (1988) conclude that the operationalized cognitive social learning variables provide a more parsimonious approach in that 
a smaller set of cognitive social learning variables produces equivalent predictive power to the set of 15 demographic and personality variables. They further suggest that the cognitive social learning variables provide a framework in which to understand the process by which the individual decides to participate in a given situation, whereas, the traditional set of variables offers no such benefit.

Florin, Jones, \& Wandersman (1988) compared the traditional demographic and personality variables to an operationalized set of cognitive social learning variables for ability to discriminate blacks who differed in their level of participation across seventeen voluntary community organizations. The results of the comparison indicated that the operationalized CSLVs and the more traditional demographic variables performed similarly in their ability to statistically predict participation. However, when the operationalized CSLVs were subjected to a Univariate $\mathrm{F}$ or chi-square test for the strength of association with the dependent variable, all five operationalized CSLVs proved to be significant. Furthermore, examination of the structure coefficients of a discriminant function analysis indicated that higher levels of participation of blacks were associated with higher perceived competencies relevant to organizing and leading groups (Construction competencies), that they placed higher value on the residential environment (subjective stimulus values), had higher expectancies of political efficacy and lower political cynicism (expectancies), and a 
higher sense of citizen duty (self regulatory plans). It was noted that perceived competencies and higher value on the residential environment were responsible for the largest contributions to the discriminate equation.

Florin, et. al. (1988) concluded that the operationalized CSLVs and the traditional set of variables, while not significantly different in their ability to predict black participation, do represent a different approach to attempting to identify the elements involved in the phenomenon of black participation. Based upon the results, they suggest that the operationalized CSLVs provide a preferred approach, given the parsimony of the set of CSLVs and the theoretical underpinnings associated with these variables which provides a framework for understanding the process involved in an individual's decision whether to participate in a given situation.

Finally, in an investigation by Florin, Wandersman, Friedman, and Meir (1992) the researchers explored a) the stability of the operationalized CSLVs across a different culture (Israel), b) the ability of the operationalized CSLVs to discriminate among different levels of participation (e.g. leaders, members, and nonmembers), and the predictive power of the CSLVs compared to a set of traditionally used variables c) levels of participation as measured by the operationalized CSLVs across two cultures (the U.S. and Israel), and d) which operationalized cognitive social learning variables best predict among 
levels of participation.

Florin et. al. (1992) found that the factor structure of the operationalized cognitive social learning variables was essentially replicated with a different sample from a different culture. Items making up each factor could be clearly identified and there were minimal intercorrelations of the items between factors.

In reference to the second question of this study, the results indicated that the operationalized cognitive social learning variables, across two different samples from two different cultures proved to be consistently stronger than a larger set of the traditional variables usually used in participation research . In both the Israeli and U.S. samples the operationalized cognitive social learning variables accounted for more variance in the criterion variable. As well, these operationalized cognitive social learning variables produced more discriminate functions, two rather than one, and correctly classified more cases than the traditional set of variables.

The operationalized CSLVs, in both samples, performed well in determining levels of participation for these samples. According to Florin et al. (1991) the variables accounted for respectable proportions of variance in the criterion variable ( $21 \%$ in the U.S. sample and $28 \%$ in the Israeli sample). The operationalized CSLVs also classified cases well above the chance level of $33 \%$ ( $55 \%$ for the U.S. sample and $64 \%$ in the Israeli sample). 
In response to the question pertaining to similarity in distinguishing level of participation across cultures, Florin et. al. (1992) discovered that while different traditional variables were related to participation in the two cultures, the operationalized CSLVs, in approximately the same relative order of importance, were related to participation in both the US. and Israeli individuals.

\section{The Model}

Previous research has compared operationalized CSLVs against traditional variables and has identified which operationalized CSLVs were most related to participation (Florin \& Wandersman, 1984). However, none of these studies has examined intercausal relationships among the operationalized CSLVs themselves. This study proposes a model which hypothesizes intercausal connections among the operationalized CSLVs and between the operationalized CSLVs and a participation criterion variable. The proposed research uses a Structural Equation Model to specify hypothesized relationships among an individual's: perceived problems in the nieghborhood; importance of nieghborhood, citizen's duty, perceived skills and past experience relevant to participation, and political cynicism. These hypothesized relationships are an attempt to model the process by which an individual decides whether to participate in a neighborhood association. Before one can ultimately consider such relationships and their implications, a model must be presented identifying the 
hypothesized relationships between the variables concerned. ( Figure I page 50, and Fighure II, page 51).

\section{Hypotheses:}

The Perception of Neighborhood Problems variable is comprised of measured items which reflect the individual's encoded view of the neighborhood as an environment. The assumption here is that the individual's encoded view of the neighborhood might influence the choice of level of participation. The Perception of Neighborhood Problems items measured the degree of satisfaction and the degree to which aspects of the neighborhood were perceived as problems. It is also assumed that the Perception of Neighborhood Problems variable is related to a number of the other variables, namely the individual's Political Cynicism and Importance of Neighborhood variable. The way an individual encodes the environment might influence the expectancies he/she will have about what might be done about the perceived problems with his/her neighborhood. For example, feeling that there are too many problems in the neighborhood might decrease an individual's expectancy that something can be done to change conditions. Similarly, Perception of Neighborhood Problems and Importance of Neighborthood are assumed to be associated. Perceiving (encoding) the environment as highly problematic and less satisfying as a living environment might lead to decreased valuing of doing something to improve the 
neighborhood. Conversely, someone who values, or cares a great deal about the neighborhood environment, yet perceives (encodes) a high degree of problems with the neighborhood, may be stimulated to act to correct the perceived problems. Thus it is hypothesized that:

Ho 1) the Perception of Neighborhood Problems variable is directly related to participation.

Ho 2) the Perception of Neighborhood Problems variable is related to Importance of Neighborhood variable.

Ho 3) the Perception of Neighborhood Problems variable is related to the Political Cynicism variable.

The Importance of Neighborhood variable measures the value of the outcome of neighborhood association activities for the individual. Mischel (1973) has suggested that given that all other variables (CSLVs) being equal for two individuals, one might participate because the neighborhood is considered more important, while another person who does not consider the neighborhood important would not participate. This valuing of the neighborhood is also assumed to effect the individual's sense of Citizen's Duty. An individual who values the neighborhood more might feel more like they have a citizen duty to participate. It is thus hypothesized that:

Ho 4) the Importance of Neighborhood variable is directly related to participation. 
Ho 5) the Importance of Neighborhood variable is related to the Citizen's Duty variable.

The Perceived Skills and Past Experiences Relevant to Participation (PSPE) variable is a measure of the individual's perceived skills for effective participation and degree of participation (frequency of involvement) in 15 community organizations where skills could be developed. An individual's perceived level of skill is assumed to be related to his/her participation. This perceived level of skills and past experiences relevant to participation, is also assumed to be related to at least two other variables, namely the individual's Citizen's Duty and Political Cynicism. It is assumed that an individual's perceived level of skill associated with the activities of participation in a neighborhood association may effect their sense of responsibility to participate in their neighborhood association, that is, those who believe they have skills will feel they should contribute them. Similarly, an individual who perceives his/herself as skilled may expect different outcomes than the individual who does not perceive his/herself to be skilled. It is thus hypothesized that:

Ho 6) the Perceived Skills and Past Experiences Relevanat to Participation variable has a direct relationship to citizen participation. Ho 7) the PSPE variable is related to the Citizen's Duty variable. Ho 8) the PSPE variable is related to the Political Cynicism variable. 
The Citizen's Duty variable is a measure of the individual's concepts of citizen duty or the feeling that one ought to participate in the political process whether such political activity is seen as efficacious or not. Thus, one's sense of citizen duty may influence one's decision to participate in a neighborhood association. Furthermore, it is assumed that the individual's sense of duty, (Citizen's Duty) could also be related to Political Cynicism. Thus, one who had a high sense of duty may have a different sense of Political Cynicism than the individual who had little feelings of citizen duty. It is thus hypothesized that:

Ho 9) Citizen's Duty has a direct relationship to citizen participation.

Ho 10) Citizen's Duty is related to the Political Cynicism variable. The Political Cynicism variable is a measure of the individual's general political beliefs. Thus, an individual who has positive political beliefs may select to participate in neighborhood association activities where the individual with cynical beliefs would not. As stated above, the Political Cynicism variable is also assumed to be related to several of the other variables, namely, the Perception of Neighborhbood Problems variable, Perceived Skills and Past Experiences relevant to Participation variable, and the Citizen's Duty variable. It is thus hypothesized that: 
Ho 11) The Political Cnyicism variable is directly related to citizen participation.

Ho 12) The Political Cynicism variable is related to the Perception of Neighborhood Problems variable.

Ho 13) The Political Cynicism variable is related to the Perceived Skills and Past Experience Relevant to Participation variable.

Ho 14) The Political Cynicism variable is related to the Citizen's Duty variable.

\section{Predictions:}

1. It is predicted that Perception of Neighborhood Problems will have a direct positive effect on Citizen Participation.

2. It is predicted that Perception of Neighborhood Problems is positively related to Importance of Neighborhood.

3. It is predicted that Importance of Neighborhood variable will have a direct positive effect on Citizen Participation.

4. It is predicted that Importance of Neighborhood is positively related to Citizen's Duty.

5. It is predicted that Perceived Skills and Past Experiences relevant to Participation will have a direct positive effect on Citizen Participation.

6. It is predicted that Perceived Skills and Past Experience relevant to Participation is positively related to Citizen's Duty. 
7. It is predicted that Percetved Skills and Past Experience relevant to Participation is positively related to Political Cynicism.

8. It is predicted that Cittzen's Duty will have a direct positive effect on Citizen Participation.

9. It is predicted that Citizen's Duty variable is positively related to Political Cynicism.

10. It is predicted that Political Cynicism will have a direct positive effect on Citizen Participation.

11. It is predicted that Political Cynicism is positively related to Perception of Neighborhood Problems.

12. It is predicted that Political Cynicism is positively related to Perceived Skills and Past Experiences relevant to Participation. 13. It is predicted that Political Cynicism is positively related to Citizen's Duty.

\section{Alternative Model}

Because evidence cannot always validate a model due to the possibility that many other models may be equally acceptable, Garrison (1986), Huba, Wingard, \& Bentler (1981), and Biddle \& Marlin (1987), suggest that confirming a model (i.e., retaining the null hypothesis) only shows that a model provides an acceptable description of the data. Thus, without legitimate alternative models for comparison, this description is the only statement that can be drawn and is a far cry from causation. Hence, researchers are strongly 
advised to compare a set of models when trying to establish important relations. This is preferred to a one-shot structural model assessment which most likely provides little evidence of causality (Bullock, Harlow, \& Mulaik, In press, 1992). Accordingly, to further check the plausibility of Model 1, an alternative model, Model 2 (Figure II) is proposed.

Research in the area of self efficacy, (Bandura, Adams, \& Beyer 1977; Bandura Adams, Hardy, \& Howell, 1980; Maddux, Norton, \& Stoltenberg, 1986) clearly has established that self-efficacy expectancy and changes in behavior are highly correlated and that self efficacy is an excellent predictor of behavior. Maddux, Norton, \& Stoltenberg, (1986) have suggested that the individual's self-efficacy expectancies or construction competencies act as powerful cognitive mediators of the individual's behavior. It can be argued that self efficacy or the belief that one has the skill to perform a task which will produce a desired outcome can be considered synonymous with Perceived Skills and Past Experience relevant to Participation variable as operationalized in the present research. Thus, an individual's decision to participate in a neighborhood association's activities may be mediated by the specific self-efficacy/construction competencies (PSPE) of the individual. Furthermore, these expectancies or construction competencies (PSPE) are assumed to be a focal point leading to the decision to participate or not. For example, an 
individual who encodes a specific situation, values the stated outcome, and feels a high sense of citizen duty (Citizen's Duty), yet who has low self efficacy expectancies/construction competencies (i.e. perceives he/she lacks commensurate skills to ensure the successful performance of the required task) will be less likely to engage in participatory behavior. On the other hand, all things being equal, with the exception of the individual's Perceived Skills and Past Experience relevant to Participation, the individual who perceives that they have commensurate skills/PSPE will be more likely to engage in participatory behavior. Thus, it can be suggested that an individual' s perceived skills (Perceived Skills and Past Expereince relevant to Participation) will directly impact his/her decision whether or not to participate in a specific situation.

Further research in the area of outcome expectancies (Maddux, Norton, \& Stoltenberg 1986) indicates that an individual's outcome expectations (i.e. the belief that a specific behavior will produce a desired outcome or Political Cynicism here) can be a powerful mediator and behavioral motivator. Thus, for the present research it is proposed that an individual's Expectancies (Political Cynicism) that are associated with an individual's decision to participate. For example, given that the individual encodes the situation, values the environment (high Importance of Neighborhood), feels a high sense of citizen duty (Citizen's Duty) and has the commensurate skills to carry 
out the behavior necessary to accomplish the desired goal and does not feel that the goal is feasible (low outcome expectancies high Political Cynicism), the decision to participate will be unlikely. In other words, the expectancies (level of Political Cynicism) of the individual will serve to mediate the individual's decision whether or not to participate. As well, the expected outcome of one's behavior (Political Cynicism) will determine whether or not he/she will particlpate in a given activity. Thus, the Perceived Skills and Past Experience relevant to Participation (PSPE) variable and the Political Cynicism variable are hypothesized to be mediating variables in Model 2.

\section{Hypotheses:}

1.) The Perception of Neighborhood Problems variable is hypothesized to have an indirect effect on Citizen Participation. This effect is hypothesized to exist through the Political Cynicism variable. It is further hypothesized that the Perception of Neighborhood Problems variable is related to Importance of Neighborhood.

2.) The Importance of Neighborhood variable is hypothesized to have an direct and indirect effect on Citizen Participation. The indirect effect is hypothesized to exist through the Perceived Skills and Past Experience relevant to Participation variable.

It is also hypothesized that the Importance of Neighborhood variable is related to the Citizen's Duty variable. 
3.) The Citizen's Duty variable is hypothesized to have an indirect effect on Citizen Participation through the Perceived Skills and Past Experience relevant to Participation variable. It is also hypothesized that the Citizen's Duty variable has an indirect relationship to Citizen Participation through the Political Cynicism variable.

4.) The Perceived Skills and Past Experience relevant to Participation (PSPE) variable is hypothesized to have both a direct and indirect effect on Citizen Participation. The individual's perceived level of skill is hypothesized to have an indirect impact Citizen Participation through the Political Cynicism variable. The PSPE variable is hypothesized to have a direct effect on Citizen Participation.

5.) The Political Cynicism variable is hypothesized to have a direct effect on Citizen Participation. 
FIGURE 1

LATENT STRUCTURE MODEL 1

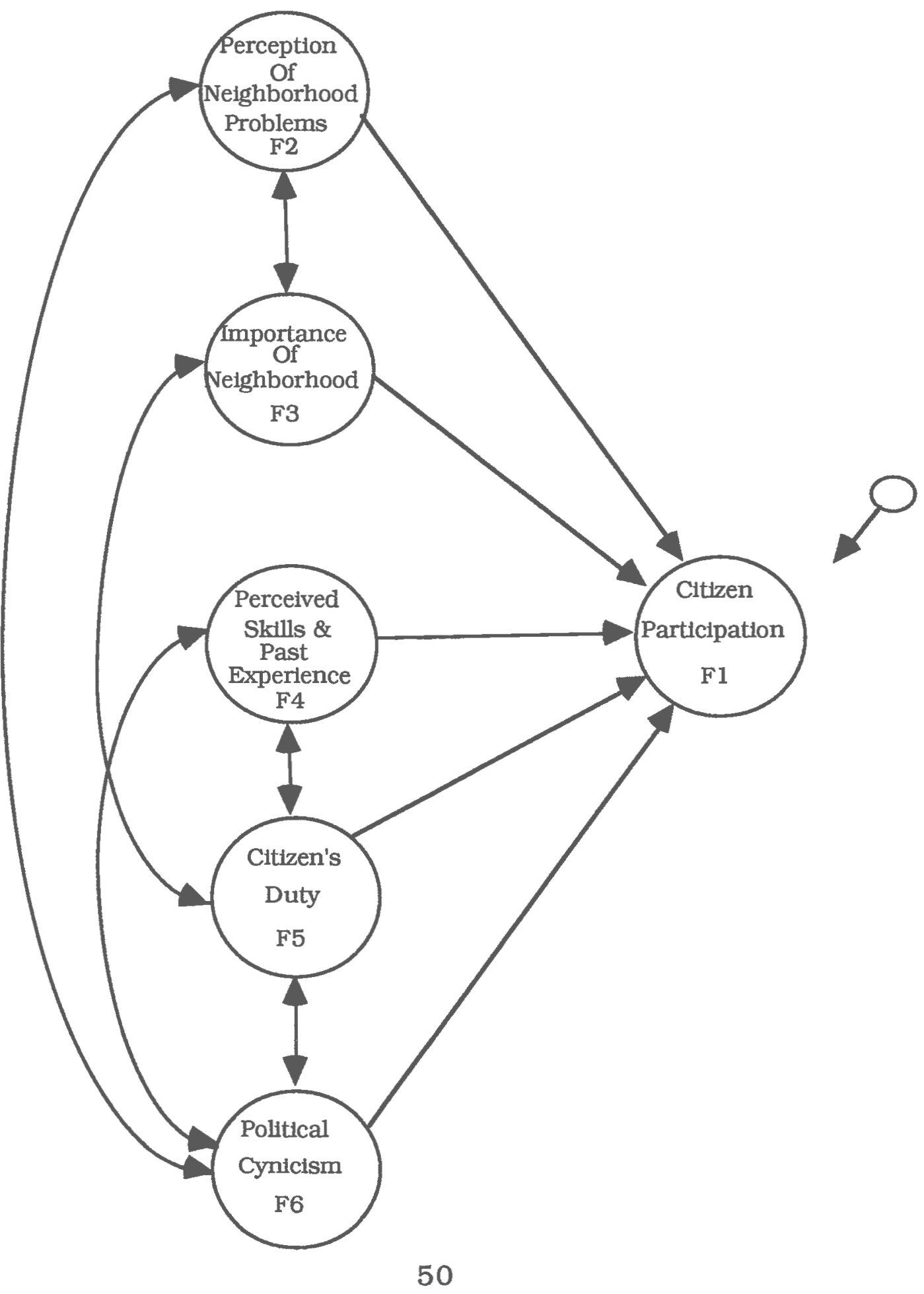


FIGURE 2

LATENT STRUCTURAL MODEL 2

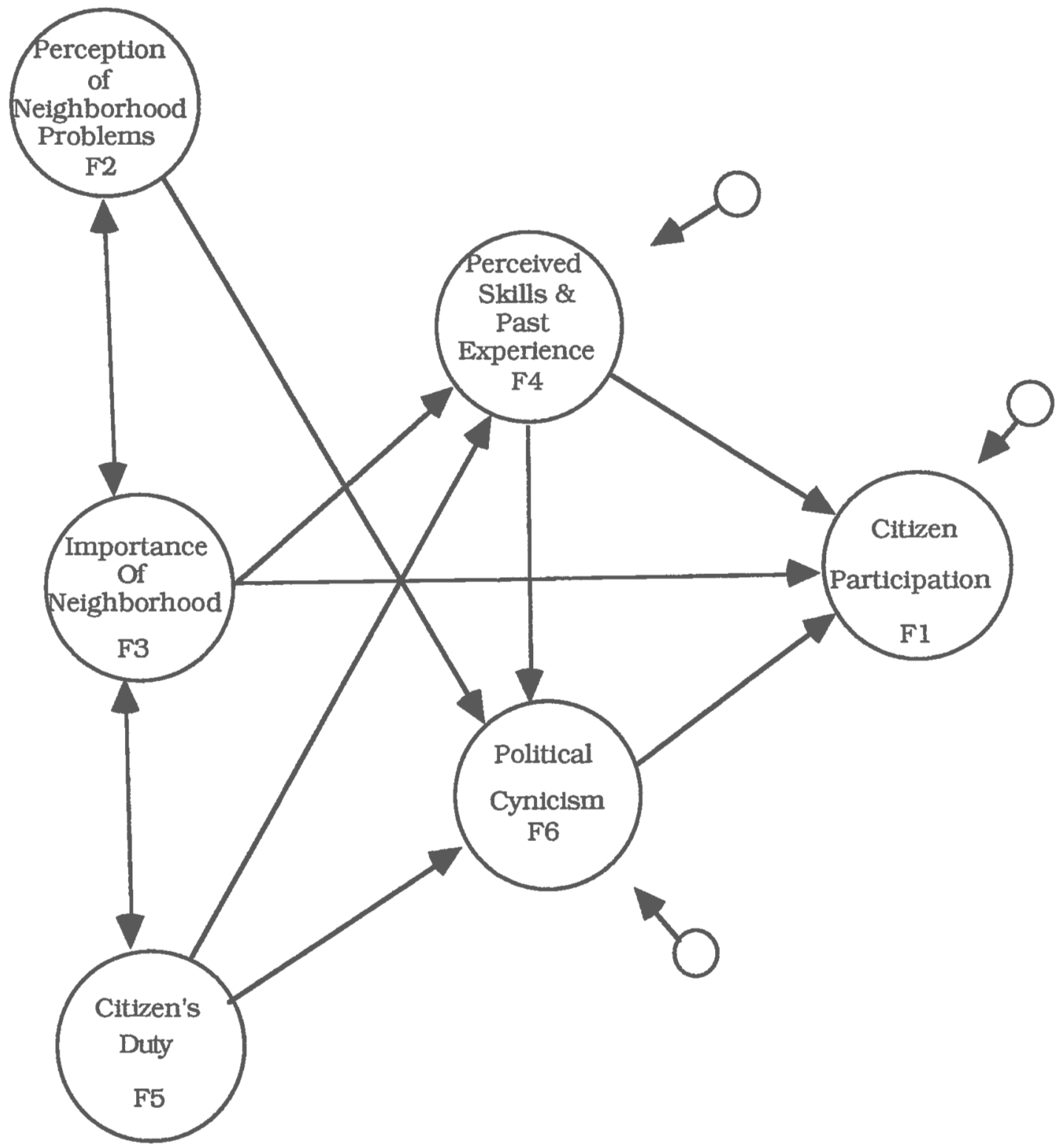




\section{Method}

\section{The Setting:}

Rapid urbanization and development of Israel left its mark on many neighborhoods which deteriorated and turned into the focal points of poverty and crime. In 1978 a national urban renewal project known as Project Renewal was initiated, which emphasized the rehabilitation of both physical and social aspects of needy neighborhoods. The project has several goals including improving the quality of the physical environment and the improvement of the quality of the social environment, and increasing the opportunities for residents to improve their own condition and the condition of the neighborhood through citizen participation. In each neighborhood, a steering committee was established to help plan and decide what programs and projects would be conducted in the neighborhood. The committee consists of 23 members, at least 11 of whom are neighborhood residents. The other members are from relevant local and national government agencies. 1 In 1985, there were 85 Project Renewal neighborhoods in Israel. Because Project Renewal is the first time that a program of widespread citizen participation has been instituted in Israel, courses on citizen participation were developed

1. The above information comes from the 1981 annual report of the International Committee for the Evaluation of Project Renewal. 
for teaching citizen participation skills and program planning. These courses were established for Project Renewal participants, but were open to others. The Israeli National Council of Schools for Neighborhood Activists used local coordinators to interview candidates in participating communities, screening and then assigning approximately 20 candidates to each "school" or course. The selected participants underwent 100 hours of courses (usually 3 hours one night a week and/or full days or weekends) lasting for about six months. By 1985 there were over 1000 graduates from 70 such schools (in close to 90 neighborhoods).

\section{Subjects:}

The respondents in Israel were 229 adult (18 years or older) Jewish Israelis. Interviews were conducted in the homes of 112 graduates of the aforementioned schools for neighborhood activists at their homes. Nationwide participating neighborhoods in which there were established school for neighborhood activists were split into southern and northern districts. Interviews were requested with every other graduate from every other neighborhood in the northern district during February and March, 1985. One Hundred and seventeen (117) nonmembers (nonactivists) were randomly selected from the same neighborhoods as these activists. Forty-nine percent of the sample were men; $86 \%$ of the sample were married. The interviews were conducted by trained interviewers and lasted 
approximately 60 minutes. Respondents were not paid.

\section{Instruments:}

The Neighborhood Activist Questionnaire (Wandersman, Florin, Friedman, \& Meier, 1987) replicated operationalized CSLVs developed in earlier research (Florin \& Wandersman 1984). For each variable, items were chosen or created which seemed particularly relevant to the specific context of participation. The questionnaire was analyzed using a Principle Components Factor Analysis (varimax rotation) $\mathrm{N}=225$. An examination of four, five and six factor solutions indicated that the five factor solution (confirming the five CSLVs) made the most sense of the data. In addition, the scree test (Cattell, 1966) for the number of factors to be retained confirmed the fivefactor solution. These five factors accounted for approximately $51 \%$ of the variance in the factor matrix (Wandersman, et. el., 1987). The results of this analysis, showing item loadings (cross-referenced to item designations from Tables 2 through 6) are presented in Table 1. The Variables:

Perceive Skills and Past Experienc Relevant to Participation is predicted by six items from the Neighborhood Activist Questionnaire. The variable needed to represent the cognitive and behavioral capabilities that might be relevant to the act of participating. Items under construction competencies were generated using a framework developed by Wiseman (1977), of requisite skills for effective 
participation in citizen advisory committees. These items measured the individual's perceived competencies in such areas as leading a group, influencing others and ability to organize people for action. These subjective perceptions were also seen as reflecting a selfefficacy expectation (Bandura, 1977). Bandura distinguishes between "outcome" expectancies or a person's estimate that a given behavior will lead to certain outcomes (identical to what is described below under expectancies) and "efficacy" expectancies or the person's belief in his or her capability to produce and successfully execute the behavior required to produce the outcomes. This distinction may be crucial in a person's choice of level of participation. Another assumption was that experience with participation in various community settings would probably provide one with the opportunity to develop skills which then could transfer to participation in a neighborhood organization. Thus, composite scores reflecting the individual's degree of participation (frequency of involvement) and leadership in 15 other community organizations (e.g. labor unions, church or synagogue, business or civic groups) were created. (Table 2 , page 61).

Perception of Neighborhood Problems is predicted by six (6) items of the Neighborhood Activist Questionnaire. The encoding variable was intended to reflect the perception and categorization of the neighborhood as an environment. The assumption here was that 
the individual's present view ("encoded view") of the neighborhood might influence the choice of level of participation. People who were more satisfied with the neighborhood as it is might be less likely to participate or not be as motivated to take as active a role as others who were less satisfled. Items were created which measured satisfaction with the neighborhood as a whole and satisfaction with specific aspects of the neighborhood (e.g., housing conditions, street conditions, safety, quietness, neatness, etc.). (Table 3, page 62).

Political Cynicism is predicted by 3 items of the Neighborhood Activist Questionnaire. Items created for the expectancies variable needed to deal with the way people might view the consequences of different actions they might take. Assuming than an expectancy for the kind of self-help action represented by a neighborhood organization might be influenced by generally held beliefs, items were included which focused on expectancies concerning grass-roots political organizations in general. Selected items from political efficacy (Campbell, Gurin \& Miller, 1954) and political cynicism (Agger, Goldstein \& Pearl, 1961) scales were modified by substituting words like "city" and "local government" for words like "country" and "government" to increase the specificity of the local focus. Agreement or disagreement with items such as "People like us don't have any say about what the local government does" and "It doesn't matter which party wins the election; the interests of the little person don't count" 
were thought to provide the context for specific expectancies for a locale-based participation. (Table 4, page 63).

Importance of Neighborhood, was predicted by 4 items of the Neighborhood Activist Questionnaire. These items attempted to assess the degree to which the individual might value the outcome of neighborhood association activities. Even if all other variables were identical for two individuals, one person might participate because the neighborhood was considered important while another person, who did not value the neighborhood as highly, might not participate. Items which directly asked about Importance of Neighborhood addressed the importance of the neighborhood as an environment to the person, the importance of a sense of community in the neighborhood, the importance of participation regardless of accomplishments, and the perceived sense of community in the neighborhood. (Table 5, page 64).

Citizen's Duty, was predicted by 4 items of the Neighborhood Activist Questionnaire. Citizen's Duty was the most difficult variable to operationalize. Because the goal was to reflect the individual's selfimposed standards of behavior, many possible reference systems came to mind.. Some individuals might have a standard of needing to be involved in anything going on around them, simply from an interest in having control over their environment. Others might have a standard of being very helpful or sociable and might find it hard to refuse to 
help a neighbor. The concept of "citizen duty" was chosen as the type of self-regulatory system appropriate to this research. Sense of citizen duty is defined as the feeling that one (and others) ought to participate in a political process, regardless of whether such political activity is seen as worthwhile or efficacious. Wording in items from the sense of citizen duty scale were modified to reflect locale based relevance. (e.g., "So many other people are active in local issues and organizations that it doesn't matter much to me whether I participate or not"). (Table 6, page 65).

\section{The Dependent Construct:}

The dependent construct in this study was measured by the level of participation in a neighborhood association. This variable was operationalized by three self report measures of involvement. The first measure, PARTIC1, was a measure of the individuals' time dedicated neighborhood activities during a typical week (Table 7, page 66). The second measure, PARTIC2, was a measure of types of activities the inidividual reported doing as a neighborhood activist (Table 8, page 67). The third measure, PARTIC3, was a self report measure the roles/tasks each individual were responsible for as a neighborhorhood activist (Table 9, page 68). 
Table 1: Factor Analysis of CSLV Items with Israeli Data ( $N=225$ )* Component Factor score coefficients

$\begin{array}{lllll}1 & 2 & 3 & 4 & 5\end{array}$

1. Perceived Skills \& Past Experience Relevant to Participation PSPE 1

PSPE2

PSPE3

PSPE4

PSPE5

.48

.36

.83

.76

.56

2. Perception of Neighborhood Problems

PNP1

PNP2

PNP3

PNP4

PNP5

PNP6

.48

.83

.85

.44

.61

.76

3. Political Cynicism

$\begin{array}{ll}\text { PC1 } 1 & .78 \\ \text { PC2 } & .69 \\ \text { PC3 } & .57\end{array}$

4. Importance Of Neighborhood

IN 1

IN 2

IN 3

IN 4

5. Citizen's Duty

CD1

CD2

CD3

* Loadings less than .30 omitted. 
Table 2: Items predicting the Latent Variable Perceived Skills and Past Experience Relevant to Participation.

PSPE1. I find it very hard to talk in front of a group.

Range 1-4; strongly disagree-strongly agree

PSPE2. Other people usually follow my ideas.

Range 1-4; strongly disagree-strongly agree

PSPE3. I am often a leader in groups.

Range 1-4; strongly disagree-strongly agree

PSPE4. I can usually organized people to get things done.

Range 1-4; strongly disagree-strongly agree

PSPE5. Index of participation in neighborhood/community groups. 15 organizations (e.g., church, PTA, sport team) were noted. Respondent indicated membership/nonmembership and extent of activity if belonged; (1) attended no meetings: (2) 12 meetings attended (3) less than half of meetings; (4) more than half attended; Range 15-60. Leadership in Community groups. Respondent was asked if he/she perceived him/herself to be a leader in any of the 15 organization listed. The affirmative responses were then totaled. 
Table 3: Items Predicting the Latent Variable Perception of Neighborhood Problems:

1 - 5 Five items asking respondent to rate neighborhood characteristics; Range 1-6

PNP1. Dangerous - Safe

PNP2. Unattractive - Attractive

PNP3. Messy - Neat

PNP4. Noisy - Quiet

PNP5. House need repair - In good condition

PNP6. All things considered, how satisfied or dissatisfied are you with this neighborhood as a place to live?

Range 1-5; very dissatisfied - very satisfied 
Table 4: Items predicting the Latent Variable Political Cynicism:

PC1. I don't think public officials in this city care much about what people like me think.

Range 1-5 Agree-Disagree

PC2. It doesn't matter which party wins the election; the interests of the little person don't count.

Range 1-5 Agree - Disagree

PC3. Political leaders usually represent the special interests of a few powerful groups and rarely serve the common needs of all citizens.

Range 1-5 Agree - Disagree 
Table 5: Items predicting the Latent variable Importance of Neighborhood:

IN1. Some people care a lot about the kind of neighborhood they live in. For other, the neighborhood is not important. How important is what your neighborhood is like to you? Range 1-5; not important - very important

IN2. How important is it to you to feel a sense of community with people in your neighborhood:

Range 1-5; not important - very important

IN3. Do you feel a sense of community with other people in this neighborhood?

(For example, do you share interests and concerns with them?) Range 1-5; not at all - a great deal

IN4. Participation in neighborhood organizations is important no matter how much or how little is accomplished.

Range 1-5 Agree - Disagree 
Table 6: Items Predicting the latent Variable Citizen's Duty:

CD1. It isn't important to get involved in local issues when you know your side doesn't have a chance to win.

Range 1-5; Agree - Disagree

CD2. A good many local elections aren't important enough to bother with.

Range 1-5; Agree - Disagree

CD3. So many other people are active in local issues and organizations that it doesn't matter much to me whether I participate or not. Range 1-5; Agree - Disagree

CD4. If a person doesn't care how a local issue is decided, he/she shouldn't participate in the decision.

Range 1-5; Agree - Disagree 
Table 7: Items comprising the Latent Dependent Construct, PARTIC1 Range 1 to 5

In a typical week could you state the number of hours you dedicate to neighborhood activities?

1. 1-2

2. $3-4$

3. $5-8$

5. $9+$ 
Table 8: Items comprising the Latent Dependent Construct: PARTIC2

1. What are the kind of activities or things you do as a neighborhood activist? Range 0-5 Response Yes - No

1. I sometimes attend meetings of various committes.

2. I regularly attend meeting of various committes.

3. I actively participat (talk, make suggestions etc) in metings.

4. I am busy in other activities in addition to committees.

5. I am chairman of a committee (steering, PTA, building). 
Table 9: Items Comprising the Latent Dependent Construct: PARTIC3 Range 0-8 Yes-No

1. What roles/tasks do you have as a neighborhood activist?

1. I Participate in activities.

2. I Plan and make decisions.

3. I Organize activities.

4. I do office work.

5. I Contact organizations.

6. I Raise money.

7. I Promote participation.

8. I Gather Information -- need assessment. 


\section{Analysis}

The proposed hypotheses will be assessed by analyzing the path diagrams presented in Figures I - II. These diagrams illustrates the proposed direct and indirect paths within the models. The type of models proposed are latent variable models, which are particularly useful in studying casual relationships. Such an approach offers several advantages. First, Structural Equation Modeling allows the use of several measures per latent factor to more fully assess each construct. This provides a richer, more valid, method of studying social science constructs which are difficult to measure with single items or variables. Second, Structural Equation Modeling allows the estimation of both measurement error (e.g. unreliability in a variable) and prediction error, which is equation error or unexplained variance in a dependent variable. This is particularly advantageous since most single variables of interest in the social sciences have some degree of measurement error which could cause bias if it is not acknowledged and taken into account during model testing. Third, Structural Equation Modeling allows for the examination of both direct and indirect effects among latent constructs. Fourth, Structural Equation Modeling allows for the examination of complex, theoretical models with hypothesized relationships among several latent variables. This is proposed as a very powerful advantage of Structural Equation Modeling over other model testing methods, because it allows more integrated 
and realistic assessment of phenomena than do univariate methods and other multivariate methods. In addition to permitting the researcher to empirically test causal relationships between variables, one may also examine the overall model. The strength of the relationship between two variables is assessed through examination of individual path coefficients. The plausibility of the hypothesized structural model can be evaluated by examining several overall fit indices including: chi square and degrees of freedom (df), the root mean square residual (RMSR), and the comparative fit index (CFI), all available in the EQS (Bentler, 1987) statistical program. 


\section{RESULTS}

Two hypothesized models of Citizen Participation were analyzed using the Bentler EQS statistical package (BMDP, Bentler 1990). Three model to data fit indices, The Maximum Likelihood Chi-Square $\left(\mathrm{X}^{2}\right)$, the Comparative Fit Index (CFI), and the Residual Mean Square Residual (RMSR) for each model performed to assess the efficiency of each Model in explaining the data. The ML Chi-Square is a fit index between the hypothesized model and the correlations among the data (Harlow, 1992). For well fitting models, the ratio of $\mathrm{X}^{2}$ to the degrees of freedom is expected to be less than 5:0. The Comparative Fit Index (Bentler, 1990) is an alternative measure of data to model fit similar to the $\mathrm{ML} \mathrm{X}^{2}$ but is less dependent on sample size. The CFI ranges between 0 and +1 with higher values, preferrably .90 and above, indicating good model to data fit. The RMSR is a measure of the closeness of fit between the model and the data. Stated differently, the RMSR provides the researcher with a measure of variance and covariance left unaccounted for by the model. According to Hayduk (1989), the value of the RMSR should be less than .06 with .03 and below signifying the optimum goal.

Each of the three indices for the two models are presented below. The results of the tested hypothesized relationships for each model are presented as are the results of a test between the two Models, the Chi-Square Difference Test. This test permits a test of fit 
between two alternative models and allows the researcher to determine which model represents the best model to data fit.

Manifest or measured variables were used to create the latent variables. The means, standard deviations, and ranges for these variables are presented in Table 10.

The analysis of Model \#1 yielded a marginal fit of the data. The ML Chi-Square statistic with $\mathrm{df}=264$, was $\mathrm{X}^{2}=481.95$. The Root Mean Square Residual (RMSR) was .068 indicating that the model exceeds the .06 rule for acceptable levels of explained variance and covariance in the data (Hayduk, 1987). The Comparative Fit Index (CFI) was .885. This index provided an additional and important indication of model fit and should be in the range of .9 to 1.0. Thus, by the three indicators of model fit, Model \#1 can be said to be a marginal fit of the data at best. The Standardized Solution factor loadings are presented in Table 11.

In such cases where prior empirical research has established strong and reliable relationships among variables, yet which yield poor model to data fit, one can reject the data or reject the model. According to Bentler $(1987,1988)$ rejecting the data would be an inappropriate solution. He suggests that minor model adjustments are a more appropriate solution for such problems in first run analysis of structural models (Bentler 1987). 
Table 10 Means, Range, \& Standard Deviations

\begin{tabular}{lllc}
\hline Variable & Mean & Range & Standard Deviation \\
\hline PNP1 & 4.63 & $1-6$ & 1.326 \\
PNP2 & 4.262 & $1-6$ & 1.481 \\
PNP3 & 3.974 & $1-6$ & 1.524 \\
PNP4 & 4.581 & $1-6$ & 1.524 \\
PNP5 & 3.917 & $1-6$ & 1.764 \\
PNP6 & 3.415 & $1-6$ & 1.067 \\
IN1 & 4.406 & $1-5$ & .741 \\
IN2 & 4.092 & $1-5$ & 1.054 \\
IN3 & 3.546 & $1-5$ & 1.121 \\
IN4 & 4.070 & $1-5$ & .939 \\
PSPE1 & 3.677 & $1-5$ & 1.214 \\
PSPE2 & 3.459 & $1-5$ & .896 \\
PSPE3 & 3.201 & $1-5$ & 1.167 \\
PSPE4 & 3.742 & $1-5$ & .955 \\
PSPE5 & 11.681 & $9-25$ & 2.936 \\
CD1 & 3.227 & $1-5$ & 2.936 \\
CD2 & 3.865 & $1-5$ & .971 \\
CD3 & 3.603 & $1-5$ & 1.141 \\
CD4 & 3.109 & $1-5$ & 1.288 \\
PC1 & 2.432 & $1-6$ & 1.232 \\
PC2 & 2.506 & $1-6$ & 1.164 \\
PC3 & 2.165 & $1-6$ & .986 \\
PARTIC1 & 1.991 & $1-5$ & 1.334 \\
PARTIC2 & 2.061 & $0-5$ & 2.710 \\
PARTIC3 & 1.410 & $0-8$ & 1.879 \\
\hline
\end{tabular}


Table 11 Model 1 Factor Loadings For Full Model 25 Variables

$\begin{array}{llll}\text { Variable } & \text { Loading } & \mathrm{E} & \mathrm{E}^{2}\end{array}$

\begin{tabular}{|c|c|c|c|}
\hline \multicolumn{4}{|l|}{$\overline{\text { Factor } 2}$} \\
\hline PNP I & $.409 *$ & .913 & .834 \\
\hline PNP2 & .818 & .576 & .327 \\
\hline PNP3 & .826 & .563 & .317 \\
\hline PNP4 & $.410^{*}$ & .912 & .832 \\
\hline PNP5 & .478 & .878 & .771 \\
\hline PNP6 & .654 & .757 & .571 \\
\hline \multicolumn{4}{|l|}{ Factor 3} \\
\hline IN 1 & .784 & .621 & .386 \\
\hline IN2 & .817 & .577 & .327 \\
\hline IN 3 & .546 & .838 & .702 \\
\hline IN 4 & $.356^{*}$ & .935 & .874 \\
\hline \multicolumn{4}{|l|}{ Factor 4} \\
\hline PSPE 1 & $.360^{*}$ & .933 & .870 \\
\hline PSPE2 & $.307^{*}$ & .952 & .910 \\
\hline PSPE3 & .783 & .621 & .386 \\
\hline PSPE4 & .691 & .723 & .523 \\
\hline PSPE5 & .471 & .882 & .778 \\
\hline \multicolumn{4}{|l|}{ Factor 5} \\
\hline CD1 & .456 & .890 & .792 \\
\hline $\mathrm{CD} 2$ & .455 & .890 & .792 \\
\hline CD3 & .767 & .642 & .412 \\
\hline CD4 & .452 & .892 & .796 \\
\hline \multicolumn{4}{|l|}{ Factor 6} \\
\hline $\mathrm{PC} 1$ & .677 & .736 & .542 \\
\hline PC2 & $.448^{*}$ & .894 & .799 \\
\hline $\mathrm{PC} 3$ & .522 & .853 & .728 \\
\hline \multicolumn{4}{|l|}{ Factor 1} \\
\hline PARTIC 1 & .893 & .451 & .203 \\
\hline PARTIC2 & .968 & .253 & .064 \\
\hline PARTIC3 & .885 & .446 & .217 \\
\hline
\end{tabular}

GOODNESS OF FIT FOR MODEL:

$\mathrm{X}^{2}=481.95$ with $\mathrm{df}=264 \quad \mathrm{RMSR}=.068 \quad \mathrm{CFI}=.885$

*Dropped from later analysis 
In order to investigate possible problems with the apparent model fit to data, the factor loadings for the model were examined (See Table 11). Since the factor loadings can be said to be the measure of the accuracy of fit between the measure and the factor, they should be in the range of .7 to .9 in cases where much is known about theory prior to model analysis. In cases where research is new or less prevalent, lower factor loadings are permissible. Examination of the loadings for Model \# 1 presented in Table 8 is revealing. Six factor loadings: PNP1, PNP4, IN4, PSPE1, PSPE2, PC2 were not fitting their respective factors. This lack of factor to variable fit is particularly evident in the cases of variables IN4 $=.356$, PSPE1 $=.360$ and PSPE2 $=.307$, indicating very poor fit when the factor loadings fall below .40 . Variables PNP1 $=.409$, PNP4 $=.410$, and PC2 $=.448$ are less troubling, yet are suspect in the model.

A further indication of the fit among variables and the hypothesized model is the size of the Absolute Standardized Residuals. According to Hayduk (1987), the Average Absolute Standardized Residual should not exceed .06. In such cases where the .06 cutoff is exceeded, a problem with model misspecification has resulted in variables which are not being explained by the model, an indication of poor model to data fit. The EQS Statistical Package (Bentler, 1987), provides a listing of the specific variables which are involved in the highest residual conflicts. A simple calculation of the difference between the 
original correlation for the conflicting variables and the residual provides an estimation of the percent of variance not being explained for such variables in the model. Examination of the Largest Absolute Standardized Residuals indicated that PNP1, PNP4, IN4, PSPE1, PSPE2, and PC2 were involved in Largest Absolute Standardized Residual Conflicts indicating that a large portion of the variance associated with these variables was not being explained by the model. Therefore they were dropped from further analysis.

Model \# 1 was submitted for analysis a second time following the decision rule for dropping variables in Confirmatory Factory Analysis proposed by Merenda (1983). Under such conditions, no factor loading below the cut off of .45 is allowed to enter the analysis. The second run included 19 of the original 25 variables. Variables PNP1, PNP4, IN4, PSPE1, PSPE2 and PC2 were dropped from the analysis. The Standardized Solution with factor loadings are shown in Table 12.

The results of the analysis conducted for the hypothesized model revealed a plausible fit of the model to the data. The ML Chi-Square Statistic with $\mathrm{df}=144$, was $\mathrm{X}^{2}=256.32$. The Root Mean Square Residual (RMSR) was $=.059$ indicating that the model was accounting for most of the variation and covariation in the data. The Comparative Fit Index (CFI) was $=.93$, which indicates good model fit. Figure 3 displays the model with its standardized parameter estimates. 
Table 12: Model 1 Factor Loadings Reduced Model

\begin{tabular}{llll}
\hline Variable Loading E & E
\end{tabular}

\section{Factor 2}

PNP2

PNP3

PNP5

PNP6

\section{Factor 3}

IN 1

IN2

IN3

Factor 4

PSPE3

PSPE4

PSPE5

Factor 5

CD1

CD2

CD3

CD4

Factor 6

PC1

PC3

Factor 1

PARTIC 1

PARTIC2

PARTIC3
.860

.786

.483

.648

.779

.829

.547

.510

.618

.876

.761

.260

.381

.767

.579

.627

.559

.837

.393

.312

.700

.800

.685

.466

.600

.729

.885

.360

.531

.783
.450

.454

.774

.451

.893

.891

.633

.893

.797

.793

.400

.797

.761

.649

.890

.421

.792

.456

$\mathrm{X}^{2}=256.32$ with $\mathrm{df}=144 \quad \mathrm{RSMR}=.059 \quad \mathrm{CFI}=.93$

$\begin{array}{lc}.892 & .452 \\ .968 & .252 \\ .885 & .465 \\ & \\ \text { RSMR }=.059 \quad \text { CFI }=.93\end{array}$

.204

.063

.216 
Table 13 Measurement Equations, Standard Error, Z Score and Significance Levels

\begin{tabular}{lcccc}
\hline Variable & Measurement & Standard Error & $\mathrm{Z}$ & $\mathrm{P}$ \\
\hline FACTOR 2 & & & & \\
PNP2 & 1.045 & .095 & 11.035 & $*$ \\
PNP3 & 1.000 & & & \\
PNP5 & .698 & .102 & 6.856 & $*$ \\
PNP6 & .570 & .061 & 9.348 & $*$
\end{tabular}

FACTOR 3

IN 1

IN2

.662

1.000

IN3

.067

9.869

.093

7.570

FACTOR 4

PSPE3

PSPE4

PSPE5

.701

1.472

.102

6.853

.261

5.628

FACTOR 5

CD1

$\mathrm{CD} 2$

1.257

.282

4.459

1.000

CD3

1.985

1.321

.384

5.163

.296

4.464

FACTOR 6

PC1

PC3

1.000

.483

.145

3.325

FACTOR 1

PARTIC 1

PARTIC2

PARTIC3

1.000

2.198

1.403

.092

.070

23.927

20.046

PATHS

PNP

$-.086$

.061

$-1.421 \quad$ NS

PARTICIPATION

IN

PARTICIPATION

.607

.107

5.696

.248

$.966 \quad$ NS

CD

PARTICIPATION

.240 
TABLE 13 (Continued)

PSPE

PARTICIPATION

PC

PARTICIPATION

\section{RELATIONSHIPS/COVARIANCES}

PNP

IN

PNP

PC

$\mathrm{CD}$

I N

$\mathrm{CD}$

PSPE

PC

PSPE

PC

$\mathrm{CD}$

.359

.301

.191

.145

.117

.241

.144

.097

3.716

.138

2.176

.081

$.979 \quad$ NS

.102

1.883 NS

.041

3.498

.042

2.810

.087

2.774

.047

3.056

Measurement Equations, Factor loadings and Regression pathways are presented in Table 13. All Factor loadings for the latent constructs were significant at the p. $<.01$ level or better (Table 12). Regression pathways for Importance of Neighborhood, Perceived Skills and Past Experiences Relevant to Participation and Political Cynicism were significant at the p. $<.01$ level while the pathways for Perception of Neighborhood Problems and Citizen's Duty were not significant. 
Table 13 indicates the hypothesized relationships and accompanying predictions for Model \#1. The Measurement Equations represent the test statistics which are univariate large-sample normal Z-tests of the null hypothesis that a given parameter is zero in the population. Large values (e.g., exceeding +/ 1.96 for a .05 size test) indicate that the null hypothesis can be rejected, i.e. that the structural coefficient is not zero (Bentler, 1990). Thus, Table 13 represents a numerical depiction of the efficiency of each of the hypothesized Pathways for Model 1. Three relationshps were predicted between the Perception of Neighborhood Problems variable and other variables. It was predicted that the Perception of Neighborhood Problems variable would have significant relationships with the a) Participation b) Importance of Neighborhood and c) Political Cynicism variables. None of these predictions were supported by the analysis. An individual's encoded view of their neighborhood (degree of satisfaction and extent of perceived problems) was_not significantly related to their level of participation, valuing of the neighborhood, and importance of the nieghborhood. As well this endcoded view was not significantly related to their belief that government officials cared about their needs, and that the common need of the citizens would be represented (Political Cynicism).

Two relationships were predicted between the Importance of Neighborhood variable and other variables. It was predicted that the 
Importance of Neighborhood variable (the individual's valuing of the neighborhood, value of a sense of community, and feeling a sense of community) would have a significant direct and positive impact on a) Participation and b) be significantly related, in a positive direction, to an individual's Political Cynicism. As indicated in Table 13, both of these relationships were supported by the analysis. Importance of Neighborhood had a direct and positive effect on Participation. Those individuals who valued the neighborhood, a sense of community and who felt more of a sense of community were individuals who participated at higher level. As well, the individual's Importance of Neighborhood was found to be related to his/her Political Cynicism (the degree to which they trusted that their government officals cared about their needs, and that the common needs of the citizens would be represented).

Three relationships were predicted between the Perceived Skills and Past Experience Relevant to Participation variable and other variables. It was predicted that the Perceived Skills and Past Experience Relevant to Participation Variable would have a) a direct and positive effect Citizen Participation b) a significant positive relationship with Citizen's Duty and c) a significant positive relationship with Political Cynicism. All of these predictions were supported by the analysis. Thus an individual's level of Perceived Skills and Past Experience Relevant to Participation (the degree to 
which the individual perceived self as a leader, the degree to which they believed they could organize people to get things done, and who had experiences in other organizations) had a direct and signficant impact on the individual's level of participation. Those individual's with higher perceived levels of PSPE participated at higher levels. In addition, Perceived Skills and Past Experience Relevant to Participation were found to be related to the individual's Citizen's Duty (the sense that it is important to become involved regardless of outcome, the sense that local elections are important, the sense that it is important to participate whether the issues is important or not, and the press to participate regardless of the number of others who participate). Finially, the individual's Perceived Skills and Past Experience Relevant to Participation were significantly related to their Political Cynicism. Those individual's who had higher perceived levels of skills required for successful particpation also had more trust that their government officals care about them and that the common need of the citizens would be represented (Political Cynicism). (See Table 13).

Three relationships were predicted between the Citizen's Duty variable and other variables. It was predicted that the Citizen's Duty variable would have a) a significant direct positive impact on Participation and b) a positive relationship with the Political Cynicism variable and c) as mentioned above, a positive relationship with the 
PSPE variable. Two of these predicted relationships were supported by the analysis. An individual's Citizen's Duty (feeling it important to be involved regardless of outcome, believing that local elections are important, participating regardless of issue importance, and feeling it important to participate regardless of the number of participants) was to be positively related to the PSPE variable. It was found that Citizen's Duty did not have a direct effect on the subjects' participation. However, the relationship, though not significant, was in the predicted direction and when a sense of citizen's duty increases so does participation.

A positive relationship between Citizen's and the Political Cynicism variable was predicted. It was found, as indicated in Table 13, Citizen's Duty had a positive and significant impact on the Political Cynicism variable. Thus, for those individuals who had higher levels of a Sense of Citizen's Duty to participate, a commensurate level of outcome Political Cynicism was observed.

It was predicted that the Political Cynicism variable would have a positive and direct effect on Participation. It was found that the relationship between Political Cynicism and Participation was in the predicted direction and that the direct relationship was significant. Those individuals who expected success were more likely to participate. (See Figure 3, page 86). 


\section{Further Examination of the Model.}

To further investigate the fit of the Model, a comparison of the Model with the original 25 variables was performed in order to assess the degree of reduction in the $\mathrm{X}^{2}$ Statistic realized by dropping the problem variables. Results revealed a significant difference Chi-Square Statistic $\mathrm{X}^{2}=225.62$, with $\mathrm{df}=105, \mathrm{p} .<.001$. This indicates that Model fit is significantly worse when variables PNP1, PNP4, IN4, PSPE1, PSPE2, and PC2 are included in the analysis (See Table 11).

To Summarize, the results of Model \#1 indicate that the Model is a reasonable representation of the data. There were several important hypotheses which were supported along with more specific predicted relationships.

For the subjects, perceived problems in the neighborhood or the subject's encoded view of the neighborhood as an environment did not significantly effect level of participation. This relationship was a negative relationship indicating that as an individual's perceptions of problems increased, participation decreased. It was found that as the individual's valuing of the neighborhood increased so did level of participation. The more skills for participation an individual possessed, the higher his/her participation level. What a subject expected to happen in a given situation was found to be positively related to participation. Though Sense of Citizen's Duty was hypothesized to have a direct effect on Participation, this hypothesis 
was not supported by the data. A Sense of Citizen's Duty did not appear as a necessary precursor to Participation.

Among the six predicted relationships, four were found to be significant. For the subjects, valuing the outcome of the neighborhood association's activities was found to be significantly related to Citizens Duty. Additionally, Sense of Citizen's Duty was found to be significantly related to the individual's PSPE or perceived skills for effective participation and experience in participation with other organizations. The subjects' Political Cynicism were found to be positively related to level of skills. As was predicted, a subject's sense of duty was positively related to his/her Political Cynicism. The subjects' perceived view of the neighborhood as an environment was not significantly related to Importance of Neighborhood or how much the individual valued the neighborhood. Finally, the subjects' encoded view of the environment was not found to be significantly related to Political Cynicism.

In order to assess how well the model accounted for variance of the individual constructs, calculations of squared multiple correlations were made. The constructs of Perception of Neighborhood Problems, Importance of Neighborhood, Perceived Skills and Past Experience Relevant to Participation, Citizen's Duty, and Political Cynicism were found to account for $46 \%$ of the variance in Participation.

This strong showing of significant path relationships between Importance of Neighborhood, Perceived Skills and Past Experience 
Relevant to Participation, and Political Cynicism points to the strength of the model in explaining a subject's reasons for participating in a neighborhood association (See Figure 3, page 86). 
FIGURE 3

STANDARDIZED SOLUTION MODEL 1

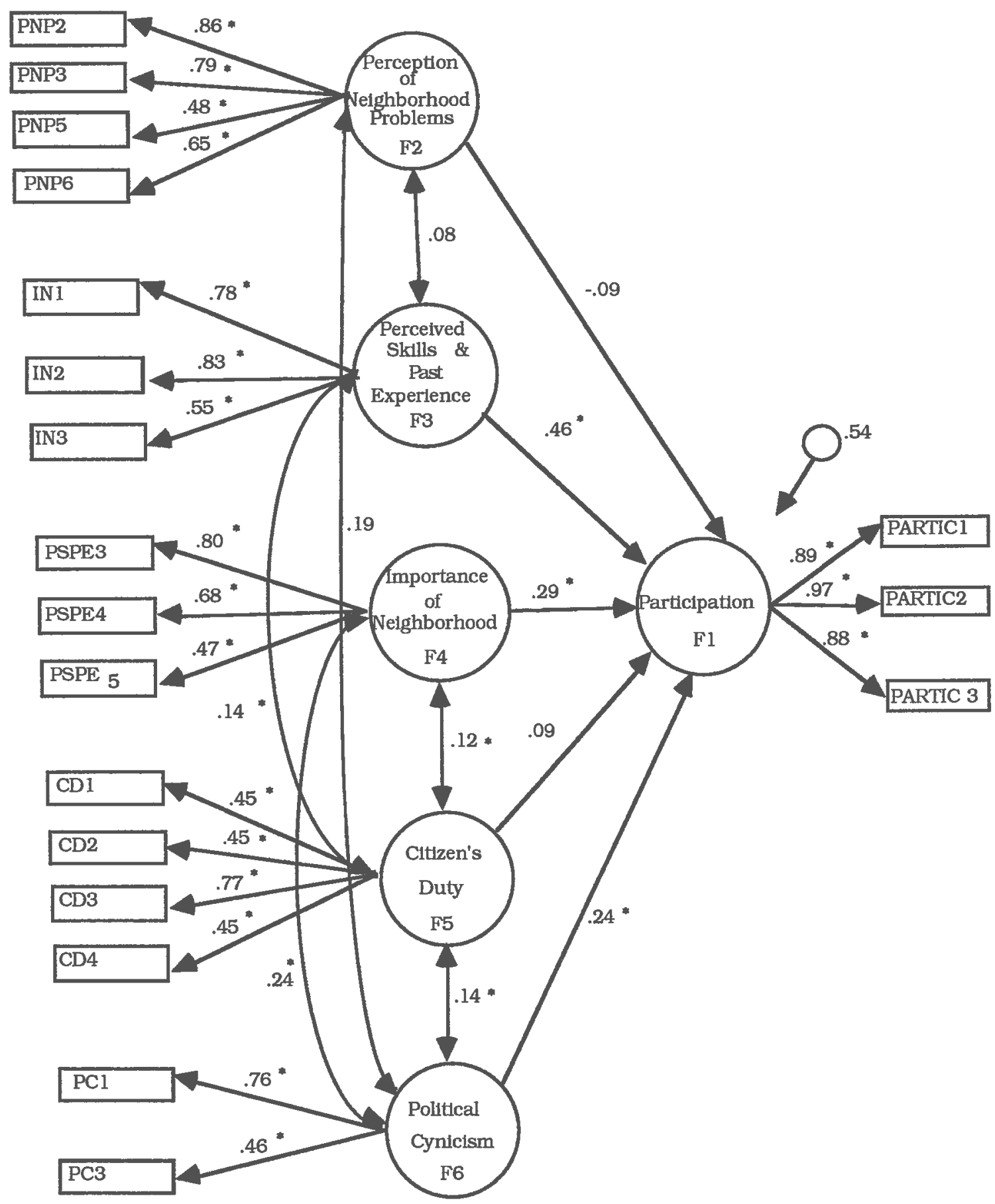

$l^{*}=$ signifficant at $\left.\mathrm{p}<.01\right)$ 


\section{Mode1 2}

The analysis of Model \#2 including all 25 variables yielded similar results to Model \#1 on the first run. When variables PNP1, PNP4, IN4, PSPE1, PSPE2, and PC2 were included in the analysis the fit of the model to the data was marginal. As indicated in Table 11, the ML Chi Square Statistic with $\mathrm{df}=264$, was $\mathrm{X}^{2}=533.385$. The Root Mean Square Residule (RMSR) was .06 indicating that the model was accounting for an acceptable level of variance and covariance in the data (Hayduk, 1987). The Comparative Fit Index (CFI) was $=.86$ indicating model to data fit below the acceptable .9 as outlined by Hayduk (1987).

Examination of the factor loadings (Table 14) indicated that variables PNP1, PNP4, IN4, PSPE1, PSPE2, and PC2 yielded poor factor to model fit as was found in the first run of Model \#1. Similar results for these variables across both models provided further evidence that they should be dropped from the analysis.

Model \#2 was submitted for analysis a second time following the decision rule for dropping variables in Confirmatory Factor Analysis proposed by Merenda (1983) and instituted for Model \#1. No variable with a factor loading below .45 was allowed to enter the analysis. The second run included 19 of the orignal variables. Variables V1=PNP1, V4=PNP4, V10=IN6, V11=PSPE1, V12=PSPE2, and V21= PC2 were excluded from the analysis. The 
Standardized Solution with factor loadings are shown in Table 15.

Table 14 Model 2 Factor Loadings For Full Model 25 Variables

\begin{tabular}{llll}
\hline \multicolumn{1}{c}{ Variable } & Loading & $\mathrm{E}$ & $\mathrm{E} 2$ \\
\hline Factor 2 & & & \\
PNP1 & $.408^{*}$ & .913 & .834 \\
PNP2 & .820 & .572 & .327 \\
PNP3 & .824 & .567 & .321 \\
PNP4 & $.409^{*}$ & .913 & .834 \\
PNP5 & .479 & .878 & .771 \\
PNP6 & .655 & .756 & .571
\end{tabular}

\section{Factor 3}

IN 1

IN2

IN3

IN 4

.802

.787

.538

$.362^{*}$

.597

.617

.843

.932

.571

.381

.711

.869

Factor 4

PSPE1

$.187^{*}$

.982

964

$.212^{*}$

.977

.954

.753

.658

433

.669

.433

.507

.743

.743

PSPE5

.862

Factor 5

CD1

CD2

.453

.968

.937

.457

.890

.792

.772

.635

.403

CD4

.461

.887

.789

Factor 6

$\mathrm{PC} 1$

PC2

PC3

.688

$.443^{*}$

.726

.527

.517

.896

.808

.856

.733

\section{Factor 1}

PARTIC1

PARTIC2

PARTIC3

.900

.968

.893
.435

.250

.451
.189

.062

.203

GOODNESS OF FIT FOR MODEL

$\mathrm{X}^{2}=533.385$ with $\mathrm{df}=264 \quad \mathrm{RMSR}=.060 \quad \mathrm{CFI}=.859$ 
Table 15 Model 2 Factor Loadings Reduced Model

\begin{tabular}{|c|c|c|c|}
\hline Variable & Loading & $\mathrm{E}$ & $\mathrm{E}^{2}$ \\
\hline $\begin{array}{l}\text { PNP2 } \\
\text { PNP3 } \\
\text { PNP5 } \\
\text { PNP6 }\end{array}$ & $\begin{array}{l}.862 \\
.785 \\
.483 \\
.648\end{array}$ & $\begin{array}{l}.507 \\
.620 \\
.876 \\
.761\end{array}$ & $\begin{array}{l}.257 \\
.384 \\
.767 \\
.579\end{array}$ \\
\hline $\begin{array}{l}\text { Factor } 3 \\
\text { IN } 1 \\
\text { IN2 } \\
\text { IN3 }\end{array}$ & $\begin{array}{l}.746 \\
.811 \\
.539\end{array}$ & $\begin{array}{l}.605 \\
.586 \\
.842\end{array}$ & $\begin{array}{l}.366 \\
.343 \\
.709\end{array}$ \\
\hline $\begin{array}{l}\text { Factor } 4 \\
\text { PSPE3 } \\
\text { PSPE4 } \\
\text { PSPE5 }\end{array}$ & $\begin{array}{l}.781 \\
.680 \\
.490\end{array}$ & $\begin{array}{l}.624 \\
.734 \\
.872\end{array}$ & $\begin{array}{l}.389 \\
.538 \\
.760\end{array}$ \\
\hline $\begin{array}{l}\text { Factor } 5 \\
\text { CD1 } \\
\text { CD2 } \\
\text { CD3 } \\
\text { CD4 }\end{array}$ & $\begin{array}{l}.450 \\
.470 \\
.783 \\
.458\end{array}$ & $\begin{array}{l}.890 \\
.882 \\
.623 \\
.889\end{array}$ & $\begin{array}{l}.792 \\
.777 \\
.388 \\
.790\end{array}$ \\
\hline $\begin{array}{l}\text { Factor } 6 \\
\text { PC1 } \\
\text { PC3 }\end{array}$ & $\begin{array}{l}.814 \\
.426\end{array}$ & $\begin{array}{l}.581 \\
.905\end{array}$ & $\begin{array}{l}.337 \\
.819\end{array}$ \\
\hline $\begin{array}{l}\text { Factor } 1 \\
\text { PARTIC } 1 \\
\text { PARTIC2 } \\
\text { PARTIC3 }\end{array}$ & $\begin{array}{l}.900 \\
.969 \\
.893\end{array}$ & $\begin{array}{l}.436 \\
.247 \\
.451\end{array}$ & $\begin{array}{l}.190 \\
.061 \\
.203\end{array}$ \\
\hline
\end{tabular}

GOODNESS OF FIT FOR MODEL 2

$\mathrm{X}^{2}=241.407$ with $\mathrm{df}=142 \quad \mathrm{RMSR}=.04 \quad \mathrm{CFI}=.939$ 
Table 16 Measurement Equations, Standard Error, Z Score and Significance Level

\begin{tabular}{lllll}
\hline Variable & Measurement & Standard Error & Z Score & P
\end{tabular}

\section{FACTOR 2}

PNP2

PNP3

PNP5

PNP6

\section{FACTOR 3}

IN 1

IN2

IN3

\section{FACTOR 4}

PSPE 3

PSPE4

PSPE5

FACTOR 5

CD1

$\mathrm{CD} 2$

CD3

$\mathrm{CD} 4$

FACTOR 6

PC1

PC3

.692

1.000

.710

1.000

.712

.099

$11.012 *$

.102

.061

$6.859 *$

9.346 *

571

.068

.095

10.209

$7.503 *$

1.000

.814

1.591

1.054

.175

.298

.231

$4.641 *$

$5.335 *$

$4.570 *$

\section{FACTOR 1}

PARTIC 1

PARTIC2

PARTIC3

\section{PATHS}

\section{FACTOR 1 PARTICIPATION}

PSPE

PC

I N
1.000

.135

$3.130 *$

1.000

2.194

1.402

.087

$25.102 *$

.067 20.934 *

FACTOR 4 PERCEIVED SKILLS AND PAST PARTICIPATION EXP.

I N

.401

.101

$3.987^{*}$

.259

.111

$2.341 *$

.626

.101

$6.208 *$
.169

.489
.108

.189

1.565

6.641
NS 
TABLE 16 Cont'd

FACTOR 6 POLITICAL CYNICISM

$\begin{array}{lllrc}\text { PSPE } & .152 & .077 & .858 & \text { NS } \\ \text { PNP } & .128 & .068 & 1.885 & \text { NS } \\ \text { CD } & .571 & .202 & 2.830 & *\end{array}$

RELATIONSHIPS/COVARIANCES

PNP

IN

.066

.077

.858 NS

$\mathrm{CD}$

IN

.225

.057

$3.914^{*}$

* p. $<.05$

Measurement Equations, Factor loadings and Regression pathways are presented in Table 13. All Factor loadings for the latent constructs were significant at the p. $<.01$ level or better. Regression pathways for Importance of Neighborhood, Perceived Skills and Past Experience Relevant to Participation, and Political Cynicism were significant at the p. $<.01$ level while the pathways for Perception of Neighborhood Problems and Citizen's Duty, were not significant. All paths were in the predicted direction.

The results of the analysis for the hypothesized model revealed a plausable fit of the model to the data. The ML Chi-Square Statistic with $\mathrm{df}=142$, was $\mathrm{X}^{2}=241.407$. The Root Mean Square Residule was $=.04$ indicating that most of the variation and covariation was being accounted for in the data. The Comparative Fit Index (CFI) was $=.94$ which indicated excellent model to data fit. Figure 4 displays the 
model with its standardized parameter estimates.

Measurement Equations, Standard Errors, and Regression Pathways are presented in Table 16. All factor loadings for the latent constructs were significant at the p. $<.01$ level or better. As indicated in Table 16, five of the eight hypothesized paths were found to be significiant. As expected, the Regression Pathways for the two latent mediating constructs, Perceived Skills and Past Experience Relevant to Participation and Political Cynicism were significant. The Regression Pathway for the latent construct Importance of Neighborhood to Participation was found to be significant. However, the Path from Importance of Neighborhood to the mediating construct, Perceive Skills and Past Experience Relevant to Participation, was not found to be significant. The path for Citizen's Duty to the mediating construct, Perceived Skills and Past Experience Relevant to Participation was found to be significant. The Citizen's Duty path to the mediating construct Political Cynicism was found to be significant. The pathway from the Perception of Neighborhood Problems construct to the mediating construct Political Cynicism was not found to be significant. The predicted relationship between Perception of Neighborhood Problems and Citizen's Duty was not found to be significant. As expected, the relationship between Importance of Neighborhood and Citizen's Duty was found to be signficiant and in the predicted direction. 
Table 16 represents the hypothesized relationships for Model \#2. It was hypothesized that the Perception of Neighborhood Problems variable would have an indirect effect on Participation through the Political Cynicism variable. It was found that the pathway from the Perception of Neighborhood Problems Variable to the Political Cynicism variable was not significant. An individual's perception of the environment and the perception of problems in the neighborhood did not signficantly influence Political Cynicism.

In addition, it was hypothesized that the Perception of Neighborhood Problems variable was related to the Citizens' Duty variable. It was found that the relationship between Perception of Neighborhood Problems and Citizen's Duty was not significant. For the subjects, the encoded view of the environment and the existence of problems in the neighborhood did not have a significant impact on Sense of Citizens Duty.

It was hypothesized that the Importance of Neighborhood variable would have a direct effect on Citizen Participation. It was found that Importance of Neighborhood had a direct effect on Citizens Participation. For the Subjects, a sense of valuing the neighborhood had a direct effect on Participation. Individuals who valued the the neighborhood were more likely to participate.

It was hypothesized that the Importance of Neighborhood variable would have an indirect effect on Participation through the mediating 
construct, Perceived Skills and Past Experience Relevant to Participation. It was found that the Importance of Neighborhood variable had a significant indirect effect on Participation through the Perceived Skills and Past Experience Relevant to Participation variable. For the subjects, individuals who valued the neighborhood also felt significantly higher levels of skills necessary for successful participation in a neighborhood association and had significantly higher levels of previous participation with other community organizations.

In addition, it was hypothesized that the Importance of Neighborhood variable was related to the Citizen's Duty. For the subjects, it was found that the Importance of Neighborhood variable was significiantly related to the Citizen's Duty variable. Individuals who valued the activities of a neighborhood association also had a higher sense of Citizen Duty.

It was hypothesized that the Citizen's Duty variable had an indirect effect on Citizen Participation through the mediating variable, Perceive Skills and Past Experience Relevant to Participation. It was found that the Citizen's Duty variable had a significant indirect effect through the Construction Competency variable. For the subjects, higher levels of sense of Citizens Duty were significantly related to the perceived skills for successful participation in a neighborhood association and to previous level of participation in other community organizations. 
It was hypothesized that the Citizen's Duty variable had an indirect effect on Participation through the Political Cynicism variable. As expected, it was found that the Citizen's Duty variable had a signficant indrect effect on Particiaption through the Political Cynicism variable. Subjects with a higher since of Citizens Duty had greater expectations of success.

It was hypothesized that the Perceived Skills and Past Experience Relevant to Participation variable had an indirect effect on Citizen Participation through the Political Cynicism variable. It was found that the Perceived Skills and Past Experience Relevant to Participation variable did not have a signifcant indirect relationship with the Political Cynicism. For the subjects, levels of perceived skills for successful participation and previous experiences with other community organizations did not effect levels of Political Cynicism.

It was hypothesized that the Perceived Skills and Past Experience Relevant to Participation variable had a direct effect on Citizen Participation. As expected, Perceived Skills and Past Experience Relevant to Participation was found to have a direct and significant effect on Citizen Participation. For the individuals with high levels of perceived skills for participation in neighborhood organizations and who had previous participatory experiences with other community organizations, participation levels were significiantly higher. 
Finally, it was hypothesized that the Political Cynicism variable would have a direct effect on Citizen Participation. It was found that the Political Cynicism variable had a direct and significant effect on citizen participation. Individuals who expected success tended to participate more.

\section{Further Examination of the Mode1}

To further investigate the fit of the Model, a comparison of the Model with the original 25 variables was performed in order to assess the degree of reduction in the $\mathrm{X}^{2}$ statistic realized by dropping the problem variables. Results revealed a significant difference chi-square statistic $\mathrm{X}^{2}=291.978$, with $\mathrm{df}=122, \mathrm{p} .<.001$. This indicates that the Model to data fit is significantly better when PNP1, PNP4, IN4, PSPE1, PSPE2, and PC2 are excluded from the analysis.

An additional investigation of the Model fit was conducted. A nested model comparison was performed to assertain the relevance of the mediating variables, Perceived Skills and Past Experience Relevant to Participation and Political Cynicism. Results revealed a significant difference chi-square statistic of $\mathrm{X}^{2}=46.114$, with $\mathrm{df}=5$, indicating that the model to data fit is significantly worse when the mediating paths are removed.

To summarize Model 2, the results indicate that the model is an excellent representation of the data. There were a number of important hypotheses which were supported. 
For the subjects, it was found that the three hypothesized direct relationships for Perceived Skills and Past Experience Relevant to Participation, Importance of Neighborhood, and Political Cynicism were supported by the data (See Figure 4). Thus, individuals who had previous participatory experiences in other community organizations and who perceived themselves to have the requisite skills for successful participation, participated more often. Individuals who valued the neighborhood also participated more often. As well, subjects who had the highest levels of outcome expectancies (Political Cynicism) also participated more.

In addition to the noted direct relationships, it was found that Perceived Skills and Past Experience Relevant to Participation and Political Cynicism play a significant role as mediating variables in participation. It was found that a Sense of Citizen's Duty has a significant impact on the individual's perceived skills for successful participation in a neighborhood association and precious participatory experiences. Those subjects with the highest levels of Citizen's Duty had the highest levels of perceived skills for successful participation and higher levels of previous experience with other organizations.

Sense of Citizen's Duty was also found to be significantly related to Political Cynicism. Those individuals who had the highest reported Sense of Cittzen's Duty had the greater expectancies of success (less Political Cynicism). In addition, Citizen's Duty was found to be 
significantly related to valuing the neighborhood. Those subjects who had the highest levels of Citizen's Duty valued the neighborhood more.

Surprisingly, it was found that the subject's encoded view of the neighborhood as an environment and the perception of problems in the neighborhood were not significantly related to his/her level of Political Cynicism. However, while this hypothesized mediating relationship was not significant, it was a negative relationship which approached statistical significance, $Z=1.88, p>.05$. This indicates that as perception of the neighborhood as an environment with multiple problems increases, participation decreases. The subject's encoded view of the neighborhood as an environment and perception of problems in the neighborhood was also found to have no impact on the subject's Valuing of the neighborhood. No significant relationship between the Perception of Neighborhood Problems $t$ and level of value was established.

Valuing the neighborhood or Importance of Neighborhood, was not found to be related to the subject's perceived skills for successful participation in a neighborhood association nor to the level of previous experiences with other community organizations. Thus, subjects who value the outcome of the neighborhood association's activities do not necessarily perceive themselves as possessing the requisite skills for successful participation and do not necessarily have previous participatory experiences in other organizations. 
It was found that the individual's perceived skills for successful participation and previous experiences in other community organizations, PSPE, are not related to his/her outcome expectancies (Political Cynicism). The hypothesis that those individuals who possessed the highest level of Perceived Skills and Past Experience Relevant to Participation would expect success was not supported by the data.

In order to assess how well the model accounted for the variance of the individual constructs, calculations of squared multiple correlations were made. The constructs of Importance of Neighborhood and Citizen's Duty were found to account for $21 \%$ of the variance in the mediating construct Perceived Skills and Past Experience Relevant to Participation $\left(\mathrm{R}^{2}=.79,1-\mathrm{R}^{2}=.21\right.$ or $\left.21 \%\right)$. The constructs Perception of Neighborhood Problems, Importance of Neighborhood, Perceived Skills and Past Experience Relevant to Participation, and Citizen's Duty were found to account for $25 \%$ of the variance of Political Cynicism $\left(\mathrm{R}^{2}=.75,1-\mathrm{R}^{2}=.25\right.$ or $\left.25 \%\right)$. Taken together, the constructs Perceived Skills and Past Experience Relevant to Participation, Political Cynicism, and Importance of Neighborhood accounted for $50 \%$ of the variance of Participation $\left(R^{2}=.50\right)$.

This strong showing of significant direct path relationships among Perceived Skills and Past Experience Relevant to Participation, Importance of Neighborhood, Political Cynicism and Participation as 
well as the significant mediating role established for Perceived Skills and Past Experience Relevant to Participation and Political Cynicism points to the strength of the model in explaining a subject's reasons for participating in a neighborhood association. (See Figure 4).

\section{Comparison of the Models}

Given the strong showing of both models as alternative explanations for participation in neighborhood associations, a comparison of Model 1 and Model 2 was conducted. A chi-square difference test for the reduction in $\mathrm{X}^{2}$ between models was made. Results revealed a significant chi- square difference statistic $\mathrm{X}^{2}=$ 14.92 , with $\mathrm{df}=2, \mathrm{p} .<.001$. This indicates that there was a significant decrease in the chi- square statistic when Model 2 was used to explain the data. Further indicators of the better model to data fit are provided in Table 14. For example, the Comparative Fit Index for Model 2 is slightly higher, .94 as opposed to .93 for Model 1 . As well, indications that more of the variance and covariance in the data is explained by Model 2 is evident in the substantially reduced RMSR $=.04$. While the RMSR for Model 1 meets the minimum criteria set by Hayduk (1987), the increased proportion of variance and covariance explained by Model 2 is preferable. Finally, the addition of the mediating pathways in Model 2 provides valuable information not included in Model 1. The existence of mediating pathways is more consistent with present day interactionist theory. 
The mediating pathways for the Perceived Skills and Past Experience Relevant to Participation and Political Cynicism variables highlight the importance of the interactionists approach to Participation research.

Table 17 Model Comparisons

\begin{tabular}{lccccc}
\hline Model & Chi Square & df & CFI & RMSR & Sig. Paths \\
\hline One & 256.32 & 144 & .93 & .06 & 3 \\
Two & 241.41 & 142 & .94 & .04 & 5 \\
\hline
\end{tabular}


FIGURE 4

STANDARDIZED SOLUTION MODEL 2

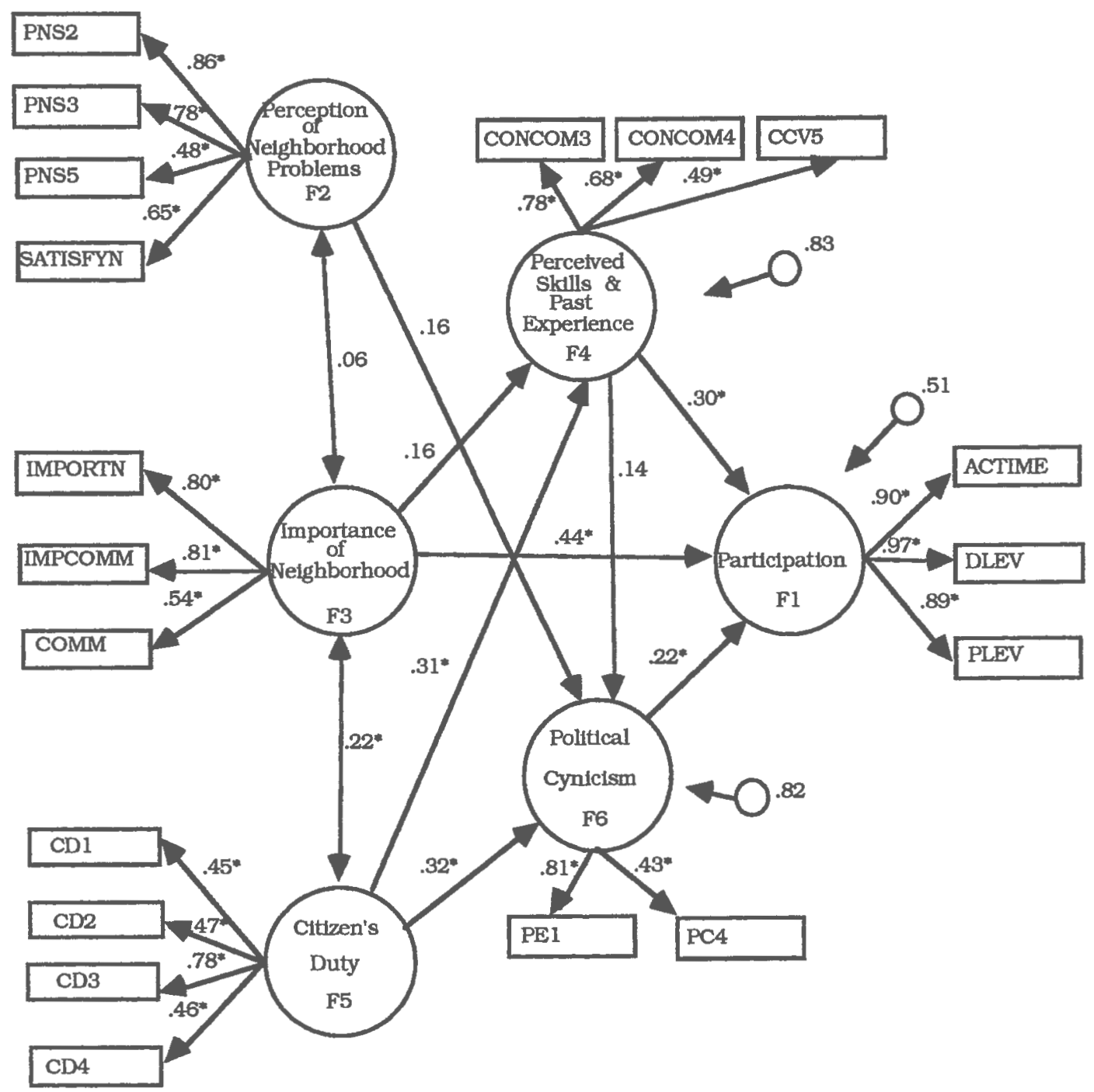

$(*=$ Significant at $\mathrm{p}<.01)$ 


\section{Discussion}

The purpose of this research was to investigate the process by which individuals decide to participate in voluntary neighborhood associations by examining the causal relationships between and among an operationalized set of cognitive social learning variables and citizen participation. A structural equation modeling procedure was utilized to test two alternative models as possible explanations of the factors that contribute to an individual's decision to participate in a neighborhood association. This statistical approach permits the examination of complex theoretical models with hypothesized relationships among several latent variables. This is a powerful advantage over other model testing methods because it allowed for more integrated and realistic assessment of phenomena than do univariate methods and other multivariate methods of analysis. A further advantage to this approach is that in addition to permitting the researcher to empirically test causal relationships between variables, one may also examine the overall model. Finally, alternative models may be compared by virtue of the Chi-Square Difference test allowing for the best model to data fit to be revealed.

The initial analysis of the data indicated that the full model, utilizing a set of 25 predictor variables of participation, was not providing adequate model to data fit. Initial indicators of the fit such as the ML Chi-Square, The Comparative Fit Index and the RMSR for 
the two models were below acceptable levels as outlined by Hayduk (1987). Examination of the factor loadings for the measurement model revealed six (6) variables that were not performing well. Imposition of the .45 decision rule for dropping variables from the analysis proved to be corrective. When the six variables were dropped from the model, good model to data fit resulted for model one and excellent model to data fit for model two. A Chi-Square Difference test comparing model to data fit between models confirmed model two as the best model to data fit. Thus, Model 2 will serve as the basis for the discussion of this research. An examination of the contributions, implications, and future directions of this research follows.

The results supported five of the eight hypothesized relationships for Model 2. Three direct relationships were supported by the data. It was revealed that a direct relationship between Perceived Skills and Past Experience Relevant to Participation and participation exists. The research indicates that those individuals who perceive themselves as leaders, who have the skills required to get people organized to get things done and who have had other previous experiences with other community associations tend to participate in neighborhood associations more often, have higher levels of participation and have spent more time participating than their counterparts. This finding is in line with prior research conducted by 
Florin and Wandersman (1984), who found that a group of operationalized CSLVs accounted for more of the variance in participation than a set of more traditional demographic variables. Their results further indicated that the Construction Competencies (Operationalized as PSPE here) variable accounted for a larger portion of the variance in the prediction equation than did any of the other CSLVs. In a related study, Whitworth (1991) found similar results. Given two sets of predictor variables, an operationalized set of CSLVs and a set of more traditional demographic variables, the operationalized CSLVs accounted for more of the variance in participation. It was also found that the Construction Competencies variable accounted for the largest portion of the shared variance in the prediction equation. In a cross-cultural study utilizing an operationalized set of operationalized CSLVs, Florin, Freidman, Wandersman, and Meier (1992) also found that Construction Competencies variable accounted for a significant proportion of shared variance across two cultures, the United States and Israel.

A direct relationship between an individual's Importance of Neighborhood and participation was confirmed. The results indicate that individuals who value their neighborhood, value a sense of community, and who have a higher felt sense of community also participate at higher levels than do their counterparts. This finding is in line with the ideas proposed by Prestby and Wandersman (1985). 
They point out that social scientists have emphasized the importance of neighborhood associations in promoting participation and providing both instrumental and social benefits for the community. The function of such organizations for the individual are four-fold, they provide: 1) an integrative function that develops community cohesion; 2) a prestige conferring role/status; 3) a problem solving role; and 4) "expressive" activities, recreation, and various forms of sociability (Jones 1983).

These four functions are understood to support a sense of community among the members (Chavis and Wandersman 1985). In another study, Chavis and Wandersman (1985), focused on the sense of community construct for its role in stimulating community development as well as other benefits for the neighborhood. A sense of community is achieved through empowerment of mediating constructs such as community organizations, the church, schools, neighborhoods, and workplace. In their analysis of blocks in which block associations were active, Chavis and Wandersman (1985) found sense of community to be related to block association participation, neighborhood relations, as well as to contribute to a sense of empowerment, and block satisfaction. In light of the present findings, sense of community (Importance of Neighborhood) appears to be an important positive determining variable in the process by which an individual decides to participate in a neighborhood organization. 
A direct relationship between an individual's Political Cynicism and Participation was revealed. This research indicates that Individuals who trust that their local government officials care about their views and who believe that those offlctals will represent the needs of the average citizen participate at higher levels. They show higher levels of time spent working in community organizations, participate in more organizations, and do more than their counter parts. The importance of the relationship of expectancies (Political Cynicism) to participation in community organizations has previously been established by the research of a number of investigators in a number of ways. For example, Florin, Mednick, and Wandersman (1985) established the relationship between expectancies (Political Cynicism) and participation as they distinguished between members, nonmembers, and leaders. Their research indicated that leaders scored lower on political cynism than did all other groups. In a similar vein, Wandersman, Florin, Freidman, and Meier (1987) found a similar relationship between Expectancies and participation in that participants with lower Political Cynicism scores participated more often than those with higher cynicism. Florin, Jones, and Wandersman (1985) in a study that investigated participation differences between Whites and Black subjects found that the individuals' perceived expectancies, (Political Cynicism) was a significant predictor of participation in both races. Thus, the direct 
relationship between and individual's Political Cynicism and participation established in this research lends to further support to the previously established relationship between Expectancies and participation in a neighborhood association.

The results further supported the hypothesis that Perceived Skills and Past Experience Relevant to Participation, and Political Cynicism play a significant role as mediating constructs in participation. Specifically, it was found that Perceived Skills and Past Experiences Relevant to Participation (perceiving one's self as a leader, believing one has the ability to organize people to get things done, and participating in other organizations) is directly influenced by the individual's Citizen's Duty. Individuals who believe that participation is important regardless of the outcome, who believe that local elections are important, who believe that participation is important regardless of the issue, and who believe it is important to participate regardless of how many others participate, are the individuals who simultaneously percelve themselves as leaders, people organizers and who have had other participatory experiences. For these individuals, Sense of Citizens Duty is directly related to Perceived Skills and Past Experience Relevant to Participation which directly related to level of participation.

One's level of Political Cynicism was also found to be a significant mediating variable in participation. The results of this research 
indicate that Political Cynicism serves as an important mediating construct for Citizen's Duty. Thus, those individuals who believe that is important to be involved regardless of outcome, who believe that local elections are important and who feel participation is important regardless of the importance of the issue tend to also believe that their local government officials care about their concerns, and that they will represent the needs of the common citizen.

Surprisingly, Perception of Neighborhood Problems was not found to be a significant variable in this research. This finding is in opposition to Henig's (1982) proposed three step-stage model of mobilization. Henig (1982) proposes that the individual perceives a condition, evaluates it as important to his or her well-being and calculates that something can be done about it. However, the present research indicates that perception of neighborhood problems, or stage one of Henig's mobilization model, was not significantly related to the individual's decision to participate in a neighborhood association. This finding has important implications discussed later in this discussion section.

The contribution of the present research is highlighted by the existence of the mediating relationships between Perceived Skills and Past Experiences Relevant to Participation, Political Cynicism and Participation. Prior research, Florin, Wandersman (1984), Wandersman, Florin, Freidman \& Meier (1987), Florin, Mednick, \& 
Wandersman (1985), had established the importance of the operationalized CSLVs. However, this research did not allow for statements about the importance of the specific variables beyond the order in which they entered the prediction equation and the amount of shared variance each accounted for in the specific research. Thus, Florin and Wandersman (1985) have shown that Subjective Stimulus Values and Expectancies have played important and significant roles in the individual's decision to participate. In fact these variables have consistently explained larger portions of the variance than competing variables in Participation research. However, the aforementioned research did not permit for statement pertaining to the interrelationships among the operationalized CSLVs within the prediction equation. On the other hand, the present research provides clear and measurable relationships among the predictor variables as both predictors and criterion measures simultaneously. By virtue of the Structural Equation Modeling approach, one can examine both direct and indirect effects, the latter being those occurring through a mediating variable (Harlow, 1992). Accordingly, Perceived Skills and Past Experience Relevant to Participation and Political Cynicism have been found to be more than just direct predictors of participation, they have simultaneously been established to be related to other variables in a mediating capacity. 
A further contribution of this research is the operationalization of the dependent construct. With the exception of the research of Prestby, Wandersman, Florin, and Meier (1991), participation has been operationalized by a single measure. Due to the flexibility of the Structural Modeling method used in the present research, multiple measures of the dependent construct were operationalized. Participation operationalized in this way offers a much richer and more realistic picture of the individual's activities. As well, the Factor Structure of the Independent Variable holds together well with each Factor Loading reaching no less than .87 (See Figure 4).

This research reveals theoretical and practical implications of investigating operationalized cognitive social learning variables. At the broadest level, the CSLV approach is a step toward an interactional psychology focused on the dynamic person- by - situation interactions. The orientation of this research relates to the inseparability of the person and the situation. In concentrating on the inseparability meaning of interaction the "reciprocal action" use of the term is advocated as well. These two meanings are closely related and the latter is best characterized by its emphasis on process over time. Therefore, the present research can best be conceptualized as a crosssectional slice of a dynamic process.

Cognitive social learning variables can best be used when the primary interest involves the prediction of behavior in a specific 
situation. The task of operationalization can serve to stimulate theoretical specificity in the substantive area. For example, Construction Competencies (PSPE here) may be operationalized to capture the specific skills necessary for the successful negotiation of a particular situation. Encoding (PNP here) might be operationalized by the specific situation permitting a degree of latitude in the conceptualization of how the individual might encode the salient situation. Mischel (1973) saw his formulation of these variables as suggestive and open to progressive revision. This could be advanced if several researchers were using the framework in different interest areas (eg., health, education).

The operationalized CSLVs also have practical implications because they are more amenable to intervention strategies. Unlike demographic variables such as age, home ownership, and race, which are difficult, if not impossible to change, operationalized CSLVs can be targeted for intervention. For example, if a primary weakness among a neighborhood's residents is their level of perceived skill, training workshops or structural changes within the neighborhood association can be made to bolster this area. If the expectancies of successful action are low among the association participants, testimonials and modeling from other, more successfully organized neighborhood associations can be arranged to enhance the participants level of expectancies. In essence, the CSLVs lend themselves to 
operationalizations specifled by characteristics of the substantive area of interest. This is a powerful advantage.

A further implication of the present research includes both theoretical and practical ramifications. As mentioned earlier, the individual's perception of neighborhood problems had no significant impact on his/her decision to participate in a neighborhood association. At a theoretical level, this finding implies that Henig's three stage mobilization model does not adequately conceptualize the decision to participate as measured in this research. Theoretically, Importance of Neighborhood or that which is conceptualized by Henig's stage two, would necessarlly preclude the importance of the individual's conceptualization of or awareness of problems in the neighborhood as a decisional factor in this model. From a more practical standpoint, individuals who seek to stimulate participation in a neighborhood association would do well to concentrate their efforts on Henig's stage two, the evaluation of the importance to well-being, as a starting point. This would entail efforts directed at increasing the importance of the neighborhood for residents. This might be accomplished by promoting activities such as block/neighborhood gatherings of a social nature where increased neighboring might occur and thereby increase the importance of the neighborhood for the individual. While this approach would not exclude the residents' awareness of specific types of problems within their neighborhood, it 
would shift neighborhood association activities toward promoting those activities that appear to be more closely associated with participation.

Taken as a whole, this research supports the proposal that the CSLVs constitute a framework that can aide in the understanding of the process by which an individual decides to participate in a neighborhood association. Variables of functional significance in the participation process may be identified and related to each other and prior research. We know for this study that perceived competencies, valuing of community and expectancies of political influence are directly related to participation. The results also suggests that the inter-relationships among the CSLVs, Construction Competencies (PSPE here) and Expectancies (Political Cynicism here) mediate the individual's decision to participate.

Unfortunately, the cross sectional nature of the data does not allow us to rule out the possibility that the aforementioned association is partially related to participation. The corrleational nature of the data do not allow for direct cause and effect statements. Longitudinal studies, where independent and dependent variables are measured at different points in time, are needed to address this issue.

A further cautionary note is indicated by the measurement model. While the Constructs associated with the model represent excellent model to data fit and thus appear to provide an acceptable theoretical 
representation of the phenomena of participation as operationalized here, a number of the variables in the measurement model proved to be poor or unreliable measures of the latent constructs. Until more effective and reliable measures can be developed, generalizations of the present findings need be tempered by caution. Cross validation of the present research should be a necessary prerequisite to confident generalization as well.

Given these results, the cognitive social learning variables appear to provide a viable and effective model for the understanding of citizen participation in community associations as described in this research. While this is an important contribution in itself, it also signifies that the present research apparently furthers the idea that the understanding of complex situations, such as that implied by citizen participation, require well conceived and carefully planned interventions. For example, mustering support for a local community organization or neighborhood association would necessarily involve addressing the three primary and direct relationship variables confirmed by this research. However, understanding that the two mediating variables, Construction Competencies and Expectancies will play a significant role in determining whether or not an individual decides to participate might offer a more accessible and direct target for intervention. Instead of trying to focus recruitment efforts on bolstering beliefs that are difficult to change, one can target areas 
which will benefit the potential member in beyond the participatory experience they are designed to promote. For example, learning the skills necessary to participate in an organization is readily transferable to other non participatory experiences. Providing such education and training in these areas then provides an incentive for those who might benefit.

Future directions include the development of more reliable measures of the operationalized CSLVs. As indicated in the introduction of this discussion, six of the original measures of the latent constructs proved to be poor measures of their respective constructs. This indicates the need for the development of items or scales which more closely tap the meaning of the identified construct. For example, the encoding variable might be reconceptualized to include qualities other than the identification of problems within the neighborhood as important characteristics leading to the encoding of percepts associated with the need or desire for action. As well, Expectancies (Political Cynicism here) might be reoperationalized to include the subject's specific outcome expectancies given a particular form of participation. This form of operationalization could more closely mirror the rather large body of research related to outcome expectancies provided by Bandura, Seligmen and others.

Additional research possibilities would include the extension of the present model to other populations and situations. For example, 
the present model could be validated through application in other participatory experiences, (e.g. citizen participation in other community organizations, schools, health settings, educational settings, businesses, etc.).

Finally, future research need to extend the identification of the present model. While five of the eight hypothesized relationships were confirmed in the present research, many more potential relationships among the constructs potentially exist. Further theoretical supports for the existence of such relationships need be discovered and then integrated into the present model providing for a more complete and conceptually superior model of citizen participation.

In conclusion, it is proposed that the Cognitive Social Learning approach explored here has considerable potential. The CSLVs can be used when primary research interests involves the prediction of behavior in a specific situation. The task of operationalizing the CSLVs can serve to stimulate theoretical specificity in the substantive area of interest (e.g., what are the specific competencies required for this particular behavior; what directions can encoding of the situation take; what dimensions in a situation might be subjectively valued, etc.) The CSLV approach contributes to the sociology and political science literature on citizen participation which has focused on individual demographic and personality variables by providing a framework 
focused on process variables. Finally, it can contribute to the practice of citizen participation, offering practical suggestions to guide interventions (Jones, 1985). 


\section{Bibliography}

Ahlbrandt, R.S. Jr. (1984). Neighborhoods, people and community, New York: Plenum

Ahlbrandt, R. S., \& Cunningham, J. V. (1979). A new public policy for neighborhood preservation. New York: Praeger.

Alford, R.R., \& Scoble, H.M. (1968). Community leadership:

Educational and political behavior. American Sociological Review, 33, 259-272.

Allport, G. W. (1937). Personality: A psychological interpretation. New York: Holt, Rinehart \& Winston.

Alterman, R., \& Frenkel, A. (1985). Implementation of project outputs: Services provided and their beneficiaries. In $\mathrm{R}$. Alterman, N. Carmon. \& M. Hill (Eds.), Comprehensive evaluation of Israel's Project Renewal (Vol. 3). Haifa: TechnionIsrael Institute of Technology, Samuel Neaman Institute for Advanced Studies in Science and Technology.

Babbie, E. (1986). The practice of social research (4th ed.) Belmont, Ca: Wadsworth.

Babchuck, N, \& Gordon, C. (1962). The voluntary Association in the Slum. University of Nebraska, Lincoln, Nebraska.

Babchuck, N., \& Thompson, R. (1962). The voluntary association of negroes. American Sociological Review, 27. 
Bandura, A. (1977). Self-efficacy: Toward unifying theory of behavior change. Psychological Review, 89, 191-215.

Bandura, A., Adams, N.E., \& Beyer, J. (1977). Cognitive processes mediating behavioral change. Journal of Personality and Social Psychology, 35, 125-139.

Bandura, A., Adams, N.E., Hardy, A. B., \& Howell, G. N. (1980). Tests of the generality of self-efficacy theory. Cognitive Therapy and Research, 4, 39-66.

Bell, W., \& Force, M. (1956). Urban neighborhood types and participation in formal association. American Sociological Review, 21, 25-34.

Bentler, P. M. (1978). The interdependence of theory, methodology, and empirical data: Causal modeling as an approach to construct validation. In D.B. Kandel (Eds.), Longitudinal Research on Drug Use. New York: Wiley \& Sons. 267-302. Bentler, P.M. (1980). Multivariate analysis with latent variables: Causal modeling. In M. R. Rosenweig \& L. W. Porter (Eds.), Annual Review of Psychology, 31. Stanford, CA: Annual Review, Inc., 419-456.

Bentler, P.M. (1987). Drug use and personality in adolescence and Young adulthood: Structural models with nonnormal variables. Child Development, 58, 65-79. 
Biddle, B. J., \& Marlin, M. M. (1987). Causality, confirmation, credulity, and structural equation modeling. Child Development, 58, 4-17.

Blau, Peter, \& Scott, Richard. (1962). Formal Organizations: $\underline{A}$ Comparative Approach. San Francisco, Ca., Chandler. Bowers, K. S. (1973). Situationism in psychology: An analysis and critique. Psychological Review, 80, 307-336.

Brager, G., \& Specht, H. (1973). Community Organizing. New York: Columbia University Press.

Bronfenbrenner, U. (1960). Personality and participation: The case of vanishing variables. Journal of Social Issues, 16, 54-63.

Bullock, H. E., Harlow, L. L. \& Mulaik, S. A. (in press, 1992). An explication of issues concerning causation in structural modeling, University of Rhode Island, \& Georgia Institute of Technology.

Carr, T., Dixon, M., \& Ogles, R. (1976). Perceptions of community life which distinguish between participants and nonparticipant in a neighborhood self-help organization. American Journal of Community Psychology, 4, 357-366.

Cassidy, R. (1980). Livable cities. New York: Holt, Rinehart, and Winston.

Cattell, R., B. (1973). Personality and mood by questionnaire. San Francisco: Jossey-Bass: 
Chavis, D. M., Florin, P., Rich, R., \& Wandersman, A. (1987). The role of block associations in crime control and community development: The Block Booster Project. Final Report to the Ford Foundation. New York: Cittzens Committee for New York City.

Chavis, D. M., Florin, P., Wandersman, A., \& Rich, R.C. (1986).. Organization development for grassroots community development organizations. Paper presented at the annual conference of the American Psychological Association.

Churchman, A. (1987). Can resident participation in neighborhood rehabilitation programs succeed? Israel's Project Renewal through a comparative perspective. In I. Altman and A. Wandersman (Eds.), Neighborhood and community environments. New York: Plenum.

Clark, Peter, \& Wilson, James. (1961). Incentive systems: A theory of Organizations. Administrative Science Quarterly, 6, 129-166. Cohen, J., \& Cohen, P. (1975). Applied multiple regressional correlations analysis or the behavioral sciences. Hillsdale, N.J.: Erlbaum.

Cole, R. (1974). Citizen participation and the urban policy process. Lexington, MA: Lexington Books. 
Draisen, M. (1983). Fostering effective citizen participation: Lessons from three urban renewal neighborhood in the Hague. In L. Sussking \& M Elliott (Eds.), Paternalism. conflict and coproduction (pp. 239-290). New York: Plenum Press. Edwards, J.N., \& White, C. (1980). Predictors of social participation: Apparent or real? Journal of Voluntary Action Research, $\underline{9}, 60-73$. Endler, N. (1973). The person-situation a pseudo issue? A response to Alker. Journal of Personality, 41, 287-303.

Endler, N. (1975). The case for person-situation interactions. Canadian Psychological Review, 16, 12-21.

Endler, N. (1976). The role of person by situation interactions in personality theory. In F. Weizmann \& I. C. Uzgiris (Eds.), The structuring of experience. New York: Plenum Press.

Endler, N., \& Magnusson, D. (Eds.), (1976). Interactional psychology and personality. Washington, D.C.: Hemisphere.

Fitch, R. T. (1991). Differences among community service volunteers, extracurricular volunteers, and nonvolunteers on the college campus. Journal of College Student Development, 32, 534-540. Fitch, R. T. (1987). Characteristics and motivations of college students volunteering for community service. Journal of College Student Personnel, 424-431. 
Florin, P., Chavis, D., Wandersman, A., \& Rich, R. (in press). A systems approach to understanding and enhancing grassroots organizations: The block booster project. In R. Leving \& H. Fitzgerald (Eds.), Analysis of dynamic psychological systems. New York: Plenum.

Florin, P., Friedmann, R., Wandersman, A., \& Meier, R. (1992). Cognitive social learning variables and behavior: Cross cultural similarities in person $\mathrm{x}$ situation behavior. Manuscript. Florin, P., \& Wandersman, A. (1984). Cognitive social learning and participation in community development. American Journal of Community Psychology, 12, 689-708.

Florin P., Jones, E., \& Wandersman, A. (1988). Black participation in voluntary associations, Voluntary Action Research, 65-86.

Freidmann, R., Florin, P., Wandersman, A., \& Meier, R. (1988). Local action on behalf of local collectives in the United States and Israel: How different are leaders from members in voluntary associations. Journal of Voluntary Action Research. 17 (3-4), 3654.

Garrison, J. W. (1986). Some principles of postpositivistic philosophy of science. Educational Research, 15, 12-18.

Godschalk, D., \& Zeisel, J. (1983). Coproducing urban renewal in the Netherlands. In L. Susskind, M. Elliot, et al (Eds.), Paternalism. conflict and coproduction. 
Goetz, R. (1979). Understanding neighborhood change. The role of expectations in urban revitalization. Cambridge, MA; Ballinger. Gottleib, B., H. \& Peters, L. (1991). A national demograqphic portrait of mutual aid group participants in Canada. American Journal of Community Psychology. 19, 5, 651-666.

Gough, H.G. (1952). Predicting social participation. Journal of Social Psychology, 35, 35, 227-233.

Gurin, P., Gurin, G., Lao, R. \& Beattie, M. (1969). Internal-external control in the motivational dynamics of Negro youth. Journal of Social Issues, 25, 29-54.

Harlow, L. (Ed.). (1992). Structrual Modeling. Packet 107. (Available from Lisa Harlow, Psychology Department, University of Rhode Island, Kingston, Rhode Island.

Harris, I. M. (1984). The citizens coalition in Milwaukee. Social Policy, 15, 9-16.

Hausknecht, M. (1962). The joiners: A sociological description of voluntary association membership in the United States. New York: Bedminster Press, West.

Hayduk, L.A. (1987). Sturctural equation modeling with LISERAL:

Essentials and advances. Baltmore: Johns Hopkins University Press. 
Heller, K., Price, R., Reinharz, S., Riger, S., \& Wandersman, A. (1984) Psychology and community change: Challenges of the future. Homewood, IL: Dorsey Press. Henig, J. (1982). Neighborhood Mobilization: Redevelopment and Response. New Jersey: Rutgers University Press. Huba, G. J., Wingard, J. A., \& Bentler, P. M. (1981). A comparison of two latent variable causal models for adolescent drug use. Journal of Personality and Social Psychology, 40, 180-193. Hyman, H. \& Wright, C. (1971). Trends in voluntary association membership of American adults: Replication based on secondary analysis of national sample survey. American Sociological Review. 36, 191-206.

Knock, D., \& Wood, J.R. (1981). Organized for action: Commitment in voluntary associations. New Brunswick, NJ: Rutgers University Press.

Kweit, M., \& Kweit, R. (1981). Implementing citizen participation in a bureaucratic society. New York: Praeger. Langton, S. (1978). Citizen Participation in America. Lexington, MA., D. C. Heath and Company.

Latting, J. K. (1990). Motivational differences between black and white volunteers. Nonprofit and Voluntary Sector Quarterly, 19. 2, $121-135$. 
Lazerwits, B. (1962). National data on participation rates among residential belts in the United States. American Sociological Review, 27, 691-696.

Levens, H. (1968). Organizational affiliation and powerlessness: A case study of the welfare poor. Social Problems, 16, 18-32.

Lindeman, R., Merenda, P. \& Gold, R. (1980). Introduction to Bivariate and Multivariate Analysis. Glenview Illinois, Scott Forseman and Company.

Litwak, E. (1961). Voluntary associations and neighborhood cohesion. American Sociological Review, 26, 258-271.

Maddux, J., Norton, L., \& Stoltenberg, C. (1986). Self-efficacy expectancy, outcome expectancy, and outcome value: Relative efficacy effects on behavioral intentions.

Magnusson, D., \& Endler, N. (1977). Interactional psychology: Present status and future prospective. In D. Magnusson \& N. Endler (Eds.), Personality at the crossroads: Current issues in interactional psychology. Hillsdale, N.J.: Lawrence Erlbaum Associates.

Merenda, P. (1983). Psychology 532: Multivariate Analysis. Unpublished notes. University of Rhode Island, Kingston, RI. Milbrath, L. W. (1965). Political participation: How and why do people get involved in politics? Chicago: Rand McNally. 
Miller, F. D., Malia, G., \& Tsmembersis, . (1979). Community. activism and the maintenance of urban neighborhoods. Paper presented to the 87th annual meeting of the American Psychological Association, New York City. Mischel, W. (1973). Toward a cognitive social learning reconceptualization of personality. Psychological Review, $\underline{80}$, 252-283.

Mischel, W. (1977). The interaction of person and situation. In D. Magnusson \& N. Endler (Eds.), Personality at the Crossroads: Current issues in interactional psychology. Hillsdale, N.J.: Erlbaum.

Moe, T.M. (1980), The Organization of Interests: Incentives and the Internal Dynamics of Political Interest Groups. Chicago: The University of Chicago Press.

Mulvihill, R. (1980). Citizen participation in the management of human settlements. New York; United Nations, Economic Commission for Europe, Committee on Housing, Build \& Planning, Doc. HBP/Sem. 26/R.6.

National Commission on Neighborhoods (1979). Neighborhoods:

People building neighborhoods. Washington: Government Printing Office

Nettles, S. (1991). Community involvement and disadvantage students: a review. Review of Educational Research, 61, 379-406. 
Olson, M. (1965). The logic of collective action. Cambridge, MA:

Harvard University Press

Orum, A. M. (1966). A reappraisal of the social and political

participation of the Negroes. American Journal of Sociology, 72,

32-46.

Piven, F. (1968). Participation of residents in neighborhood

community action programs. In H.B. Spiegel (Ed), Citizen

participation in urban development. (Vol 1), Washington, D.C.:

NTL Institute.

Parkum, D. \& Parkum V., (1980). Citizen participation in community planning and decision making. In D. H. Smith (ed), Participation in Social and Political Activities. San Francisco. Jossey-Bass.

Perkins, D. D., Florin, P., Rich, R., Wandersman, A., \& Chavis, D. M. (1990). Participation and the social physical environment of residential neighborhoods: Crime and community context. American Journal of Community Psychology, 18, 83-115.

Perrow, C. (1970). Members as resources in voluntary organizations. In W. R. Rosengren, \& M. Lefton (Eds.), Organization and clients. Columbus, Ohio: Merrill.

Prestby, J. E., Wandersman, A., Florin, P., Rich, R., \& Chavis, D. (1990). Benefits, costs, incentive management and participation in voluntary organizations: A means to understanding and promoting empowerment. American Journal of Community 
Psychology, 18(1).

Prestby, J.E. (1984). Leaders and members in voluntary organization. Working paper, Department of Psychology, University of South Carolina.

Rohe, W., \& Gates, L. (1981). Neighborhood planning: Promise and product. The Urban and Social Change Review. 14.

Rohe, W., \& Gates, L. (1982). Neighborhood planning and citizen influence. Pater presented at the Urban Association meeting. Philadelphia, PA.

Sanger, P. \& Alker, H. (1972). Dimensions of internal-external locus of control and the Women's Liberation movement. Journal of Social Issues, 28, 115-129.

Schoenberg, ., \& Rosenbaum, P. L. (1980). Neighborhoods that work: Sources of viability in the inner city. New Brunswick, NJ: Rutgers University Press.

Scott, J. C., Jr. (1957). Membership and participation in voluntary association. American Sociological Review, 22, 315-326. Sills, David. (1968). Voluntary associations: Sociological aspects. in David Sills, (Eds.) International Encyclopedia of the Social Sciences, 16. New York, Macmillian and Free Press. Smith, D.H. (1975). Voluntary action and voluntary groups. In A. Inkels, J. Coleman, \& N. Smelser (Eds.), Annual Review of Sociology, (Vol 1), Palo Alto: Annual Reviews. 
Smith, C. \& Freeman, A. (1978). Voluntary Associations:

Perspectives on the Literature. Cambridge, MA., Harvard University Press.

Tomeh, A. K. (1974). Formal voluntary organizations: Participation correlates and interrelationships. Sociological Inquiry, 43, 89122.

Unger, L. . (1991). Altruism as a motivation to volunteer. Journal of Economic Psychology, 12, 71-100.

Vassar, . (1978). Community participation in a metropolitan area: An analysis of the characteristics of participants.

Unpublished doctoral dissertation, University of Illinois at Chicago.

Verba \& Nie, N. (1980). Participation in America. Political participation and social equality. New York: Harper \& Row. Wandersman, A., \& Florin, P. (1981). A cognitive social learning approach to the crossroads of cognition, social behavior and environment. In John Harvey (Ed.). Cognition, social behavior and environment. New York: Lawrence Erlbaum.

Wandersman, A., Florin, P., Friedman, R., \& Meier, R. (1987). Who participates, who does not, and why? An analysis of voluntary neighborhood organizations in the United States and Israel. Sociological Forum 2,534-555. 
Wandersman, A., Unger, D., Florin, P. and Chavis, D. (in press).

Impacts of small-scale community development associations.

Windmer, C. (1984). An incentive model of citizen participation

applied to a study of human service agency boards of directors.

Ph.D. dissertation, Cornell University.

Whitworth, D. (1991). Traditional demographic and cognitive social

leanring variables as predictors of levels of voluntary community

participation. Unpublished Master's Competancy, University of

Rhode Island, Kingston, Rhode Island.

Williams, J., Babchuk, N., \& Johnson, D. (1973). Voluntary

associations and minority status: A comparative analysis of

Anglos, Blacks, and Mexican Americans. American Sociological

Review, 38, 637-646.

Williams, J., \& Ortega, ., (1986). The multidimensionality of

joining, Journal of Voluntary Action Research, 15, 35-44.

Yin, R. k., \& Yates, D., (1974). Street-level governments: Assessing

decentralization and urban services. Santa Monica, CA: Rand

Zehner, R. B. (1972). Neighborhood and Community Satisfaction:

Assessing Decentralization and Urban Services. Santa Monica,

CA: Rand 